\title{
Origins of Grape and Wine Aroma. Part 1. Chemical Components and Viticultural Impacts
}

\author{
Anthony L. Robinson, ${ }^{1,2}$ Paul K. Boss, ${ }^{3}$ Peter S. Solomon, ${ }^{4}$ \\ Robert D. Trengove, ${ }^{1}$ Hildegarde Heymann, ${ }^{5}$ and Susan E. Ebeler ${ }^{5 *}$
}

\begin{abstract}
Wine is an ancient beverage and has been prized throughout time for its unique and pleasing flavor. Wine flavor arises from a mixture of hundreds of chemical components interacting with our sense organs, producing a neural response that is processed in the brain and resulting in a psychophysical percept that we readily describe as "wine." The chemical components of wine are derived from multiple sources; during fermentation grape flavor components are extracted into the wine and new compounds are formed by numerous chemical and biochemical processes. In this review we discuss the various classes of chemical compounds in grapes and wines and the chemical and biochemical processes that influence their formation and concentrations. The overall aim is to highlight the current state of knowledge in the area of grape and wine aroma chemistry.
\end{abstract}

Key words: monoterpenes, norisoprenoids, alcohols and esters, phenylpropanoids, methoxypyrazines, volatile sulfur compounds

Chemists have isolated and analyzed the composition of foods and beverages for centuries in an attempt to identify and quantify those chemicals responsible for the human experience of smell and taste. An early pioneer was the Swedish chemist Carl Wilhelm Scheele (1742-1786), who isolated organic acids including citric, lactic, malic, and tartaric acids from lemon, milk, apple, and unripe grape, respectively (Scheele and De Morveau 2009). Grapes and wine have been important products for such compositional studies due not only to their contribution to the world economy and culture but also to their complexity, which has inspired scientists.

Although compositional studies can provide information about the compounds contributing to the sensory perception of wines, they cannot replace humans in their ability to translate the complex interactions of sight, smell, and taste that define the sensory experience of consuming wine. That is because flavor is an interaction of consumer and product (Piggott 1990). It is the culmination of multiple volatile and nonvolatile compounds present in the product (Rapp and Mandery 1986, Rapp 1998b, Ebeler 2001, Polášková et al. 2008) and an equally complex receptor and perception system that is closely linked to neural systems in the brain used for

\footnotetext{
${ }^{1}$ Separation Science and Metabolomics Laboratory, Murdoch University, Murdoch, WA 6150, Australia; ${ }^{2}$ Treasury Wine Estates, P.O. Box 396, Nuriootpa, SA 5355, Australia; ${ }^{3}$ CSIRO Plant Industry, P.O. Box 350, Glen Osmond, SA 5064, Australia; ${ }^{4}$ Plant Science Division, Research School of Biology, Australian National University, Canberra, ACT 0200, Australia; and ${ }^{5}$ Department of Viticulture and Enology, University of California, Davis, CA 95616 USA. *Corresponding author (seebeler@ucdavis.edu; tel: 530-752-0696; fax: 530752-0382)

Acknowledgments: The authors thank the Australian Grape and Wine Research and Development Corporation and the Australian-American Fulbright scholarship program for financial support for ALR.

Manuscript submitted May 2012, revised Oct 2013, accepted Nov 2013

Copyright (C) 2014 by the American Society for Enology and Viticulture. All rights reserved.

doi: $10.5344 /$ ajev.2013.12070
}

learning, memory, emotion, and language (Buck and Axel 1991, Mori et al. 1999, Swiegers et al. 2005b, Shepherd 2006, Auvray and Spence 2008).

The goal of this review is to present a summary of literature relevant to the field of wine aroma research highlighting, in Part 1, the current state of our knowledge concerning grape and wine composition. In Part 2 we review the analytical and sensory techniques used in this research field. While we have attempted to be as comprehensive as possible, we focus largely on research from the past $\sim 15$ years. The reader is also referred to other excellent reviews on grape and wine aroma for emphasis in areas not covered here (e.g., Lund and Bohlman 2006, Styger et al. 2011, Qian and Shellhammer 2012, Sáenz-Navajas et al. 2012, González-Barreiro et al. 2013, Villamor and Ross 2013).

\section{Origins of Wine Aroma}

The origins of wine aroma and bouquet (here referred to collectively as aroma) have been of major interest over the last century, with advances made through the development and use of modern analytical techniques coupled to hybrid analytical/sensory methods (Guth 1997b, López et al. 1999, Ferreira et al. 2000, Francis and Newton 2005, Polášková et al. 2008, Ebeler and Thorngate 2009) and through multivariate statistical comparisons with descriptive sensory analysis (Noble and Ebeler 2002, Lee and Noble 2003, 2006, Escudero et al. 2007, Sáenz-Navajas et al. 2010). The combination of analytical and sensory methodologies has been particularly important in resolving effects of interactions of aroma compounds with the nonvolatile matrix (Pineau et al. 2007, Robinson et al. 2009, Sáenz-Navajas et al. 2010) as well as with other volatile compounds (Atanasova et al. 2005, Escudero et al. 2007, Pineau et al. 2009). These interactions may result in variations in the sensory character of the mixture due to perceptual enhancement and suppression effects as well as to physicochemical effects on volatility and release of the aroma compounds. 
The sensation of flavor occurs when odor-active molecules stimulate sensors in the mouth and nose, which the brain collates to produce a flavor perception (Taylor 1998). The current understanding is that multiple sensory interactions occur in the perception of flavor, including olfactory, gustatory, and trigeminal sensations (Auvray and Spence 2008, ISO 1985), where smell plays a particularly important role in the overall perception of the product (Shepherd 2006, 2007).

Smell is a biological and electrophysiological process that converts the molecular information of an odorant into a perceptual response (Hasin-Brumshtein et al. 2009). The human olfactory epithelium accommodates millions of olfactory sensory neurons that are attached to olfactory receptors, each capable of detecting multiple compounds with common functional groups. At the same time, multiple different receptors can recognize the same odor compound if multiple functional groups are present (Firestein 2001, Hasin-Brumshtein et al. 2009). Currently, 347 potentially functional olfactory receptor genes have been identified (Zozulya et al. 2001, Gaillard et al. 2004), allowing humans to detect the thousands of odor compounds found in nature.

Wine aroma is derived from multiple sources and processes, including:

- The direct contribution of grape-derived aroma compounds, including monoterpenes, norisoprenoids, aliphatics, phenylpropanoids, methoxypyrazines, and volatile sulfur compounds (Ebeler and Thorngate 2009, Gonzalez-Barreiro et al. 2013).

- Microbially derived secondary metabolites formed from metabolism of sugar, fatty acids, organic nitrogen compounds (pyrimidines, proteins. and nucleic acids), and cinnamic acids found in grape (Chatonnet et al. 1992, Herraiz and Ough 1993, Guitart et al. 1999, Hernández-Orte et al. 2002, Swiegers et al. 2005a, Bartowsky and Pretorius 2009).

- The contribution of oak-derived aroma compounds that are extracted during fermentation and storage of wine and that vary depending on the origin, seasoning, and heating of the wood (Sefton et al. 1990, Francis et al. 1992, Cadahía et al. 2003, Gómez-Plaza et al. 2004, Garde-Cerdan and Ancin-Azpilicueta 2006, Fernández de Simón et al. 2010a, Garde-Cerdan et al. 2010).

- Chemical changes associated with acid (Skouroumounis and Sefton 2002, Versini et al. 2002) and enzyme-catalyzed (Günata et al. 1985, Sefton and Williams 1991, Ugliano 2009) modification of both nonaroma active and aroma active (e.g., terpenes; Rapp 1998a) grape constituents.

- Chemical modifications associated with oxidative processes in wine (Simpson 1978, Escudero et al. 2002, Silva Ferreira et al. 2002), which are related to oxygen uptake from winery operations, storage, and packaging materials (Karbowiak et al. 2009, Ghidossi et al. 2012).

While a number of aroma compounds have been identified, an understanding of the role viticulture plays in their evolution remains limited. This may be attributed to time and cost limitations in conducting viticultural studies and to great emphasis in the past on analytical method development and compound discovery as well as difficulty in identifying and quantifying trace grape components that contribute to final wine aroma.

\section{Volatile Compound Classes Found in Wine}

The advent of gas chromatography and gas chromatography coupled to mass spectrometry has resulted in the identification of hundreds of aroma compounds in many foods, including wine (Ohloff 1978). The major groups of aroma compounds found in wine are monoterpenes, norisoprenoids, aliphatics, higher alcohols, esters, phenylpropanoids, methoxypyrazines, and volatile sulfur (Francis and Newton 2005, Ebeler and Thorngate 2009). Numerous studies have investigated the composition of specific grape cultivars in an effort to better understand the origins of varietal aroma (Sefton et al. 1993, 1994, 1996, Schneider et al. 2002). In some instances these studies have been successful in distinguishing cultivars according to key compounds or dominant groups of aroma-active compounds (Noble et al. 1980, Günata et al. 1985, Rosillo et al. 1999, Sefton et al. 1993). However, few studies have been able to identify a defining compound responsible for varietal character. It is apparent that varietal character is dependent, therefore, not on a particular compound but on the overall profile of odor-active compounds present in the grape and corresponding wine. The following sections provide a survey of the compounds found in grapes and wines grouped according to their functional groups.

\section{Terpenes}

Monoterpenes and sesquiterpenes are biologically synthesized from isopentyl pyrophosphate (IPP) and dimethylallyl pyrophosphate (DMAPP). These precursors are formed either through the cytosolic mevalonic-acid (MVA) pathway from three molecules of acetyl-CoA (Newman and Chappell 1999) or through the plastidial 2-C-methylerythritol-4-phosphate (MEP) pathway from pyruvate and glyceraldehyde-3-phosphate (Rohmer 1999). Monoterpenes are subsequently formed from 2E-geranyl diphosphate (GPP) and sesquiterpenes are formed from 6E-farnesyl diphosphate (FPP) through the action of terpene synthases (TPS) (Lücker et al. 2004, Martin et al. 2010). The Vitis vinifera terpene synthase (VvTPS) gene family contains the largest number of functionally characterized TPS for any species reported to date (Martin et al. 2010). Overall, $39 V v T P S$ gene products have been functionally characterized, demonstrating that this gene family is capable of synthesizing upward of 21 different monoterpenes and 47 sesquiterpenes (Martin et al. 2010).

Monoterpenes are important contributors to the aroma of white wines made from Muscat varieties (e.g., Muscat of Alexandria, Muscat de Frontignan) and aromatic non-Muscat varieties (e.g., Gewürztraminer, Riesling) (Ribéreau-Gayon et al. 1975, Rapp 1998b, Mateo and Jimeńez 2000). Correlations between floral sensory attributes and high levels of free linalool and $\alpha$-terpineol in these varieties have been well documented (Williams et al. 1981, Günata et al. 1985, Wilson et 
al. 1986, De La Presa-Owens and Noble 1997, Lee and Noble 2003, 2006, Campo et al. 2005). In addition, (Z)-rose oxide has been identified as an important impact aroma compound in Gewürztraminer wines (Guth 1997a) and is associated with the lychee aroma attribute common to this variety (Ong and Acree 1999). Finally, the monoterpene "wine lactone" is an important aroma component in Gewürztraminer wines (Guth 1997a, 1997b). Other aromatic cultivars or non-Muscat cultivars, of which the most common example is Riesling, contain lower levels of free monoterpenes compared to the Muscat varieties (Dimitriadis and Williams 1984, Günata et al. 1985, Razungles et al. 1993). Biosynthesis of monoterpenes in these varieties was associated with a gene called $V v D X S$ (Battilana et al. 2009, 2011). This gene codes for a key enzyme early in the terpene synthesis pathway (1-deoxy-D-xylulose-5-phosphate synthase) and has been shown to be associated with production of terpenes in Muscat varieties and Muscat-like aromatic mutants (Emanuelli et al. 2010).

Red varieties are not phenotypically characterized by high levels of terpenes, although low levels of some terpenes are usually present (e.g., $<1.5 \mu \mathrm{g} / \mathrm{kg}$ linalool, citronellol, nerol, and geranyl/neryl acetone in Cabernet Sauvignon grapes; Canuti et al. 2009). However, numerous genes involved in isoprene/terpene metabolism have been identified in grapes, which may point to an important evolutionary role of terpenes in grape development and/or pest and disease resistance (Jaillon et al. 2007, Martin et al. 2010, Stitt et al. 2010).

Twenty previously unidentified monoterpenes were recently identified in Fernão-Pires grapes from Portugal (Rocha et al. 2007), suggesting that yet undiscovered terpenes may occur in grapes. In addition, a number of monoterpenes are subject to transformations under the $\mathrm{pH}$ and temperature conditions found in juice and wine (Rapp 1998a, Raguso and Pichersky 1999), and thus grape biosynthesis may not explain all terpene metabolites found in wine. For example, under acidic conditions, degradation of geraniol and linalool results in formation of linalool oxides and $\alpha$-terpineol (Baxter et al. 1978, Haleva-Toledo et al. 1999, Skouroumounis and Sefton 2000, Silva Ferreira et al. 2002, Varming et al. 2004, 2006). The reactions are greater at higher temperatures such as those that may occur during transport or storage and may contribute to aged characters in wines (Silva Ferreira et al. 2002).

Finally, monoterpenes in wine may also arise from nongrape materials in and around vineyards (Rocha et al. 2007). For example, evidence suggests that 1,8-cineole (eucalyptol), while probably synthesized in Cabernet Sauvignon berries soon after set (Kalua and Boss 2009, 2010), can also originate from matter other than grape, especially material from eucalyptus trees in and around vineyards (Capone et al. 2012).

Sesquiterpenes have gained little attention with respect to grape and wine analysis, with only three major studies reporting multiple sesquiterpenes in Riesling, Traminer, Ruländer, Müller-Thurgau, Scheurebe, Optima, Rieslaner, Baga, and Shiraz grape varieties (Schreier et al. 1976, Coelho et al. 2006, Parker et al. 2007). The sesquiterpene $\alpha$-ylangene was identified as a candidate marker of pepper character in Australian Shiraz wines, but its aroma contribution to wine could not be confirmed (Parker et al. 2007). The sesquiterpene rotundone was subsequently identified as the potent aroma-impact compound responsible for the black pepper aroma in wines produced from Vitis vinifera $\mathrm{cv}$. Shiraz (Siebert et al. 2008, Wood et al. 2008) as well as in a number of other plants including black pepper (Piper nigrum), marjoram (Origanum majorana), oregano (Origanum vulgare), geranium (Pelargonium alchemilloides), nut grass (Cyperus rotundus), rosemary (Rosmarinus officinalis), saltbush (Atriplex cinerea), basil (Ocimum basilicum), and thyme (Thymus vulgaris) (Wood et al. 2008).

Clearly, terpenes and sesquiterpenes play important roles in a number of different winegrape varieties. With continuing discoveries of important new compounds, such as rotundone, it is clear that this group of compounds will continue to be a focus of wine aroma research into the future.

\section{Norisoprenoids}

Norisoprenoids (or apocarotenoids) are derived from carotenoids, are found commonly in nature, and have attracted considerable attention as odorants in many food and fragrance products (Baumes et al. 2002, Winterhalter and Rouseff 2002, Winterhalter and Ebeler 2013). They consist of a megastigmane carbon skeleton and differ in the position of the oxygen functional group, being either absent (megastigmanes), attached to carbon 7 (damascones), or attached to carbon 9 (ionones) (Winterhalter and Rouseff 2002). Norisoprenoids are ubiquitous among grape cultivars, although they are most abundant in aromatic cultivars (Strauss et al. 1987, Winterhalter et al. 1990a, Marais et al. 1992, Schneider et al. 2001), and they are thought to play an important role in the aroma of many wine varieties including Semillon, Sauvignon blanc, Chardonnay, Merlot, Syrah, and Cabernet Sauvignon (Razungles et al. 1993, Sefton et al. 1993, 1994, 1996, Sefton 1998).

Grape carotenoid precursors. Since norisoprenoids are derived from carotenoids, it follows that the abundance of norisoprenoids can be influenced by the carotenoid profiles of berries. Carotenoids fill an important photoprotective role in plant tissue by either scavenging singlet oxygen or by quenching the triplet state chlorophyll, thereby preventing the formation of singlet oxygen, a powerful oxidant that can damage cell membranes and proteins (Demmig-Adams 1990, Young 1991, Demmig-Adams and Adams 1996). Additionally, carotenoids are found to improve photosynthetic efficiency in higher plants as accessory light harvesters. In grapes, carotenoids and xanthophylls are generated in chloroplasts (Baumes et al. 2002). During grape maturation, when chloroplasts are lost (Hardie et al. 1996), levels of carotenoids, along with chlorophyll, decrease (Razungles et al. 1988, 1993).

More than 600 carotenoids and xanthophylls, with a diverse range of structures, have been isolated from natural sources (Britton 1995). Only a few of these, however, have been identified in grapes and wines. $\beta$-Carotene and lutein constitute $85 \%$ of the total, with neochrome, neoxanthin, violaxanthin, luteoxanthin, flavoxanthin, lutein-5,6-epoxide and zeaxanthin, and cis isomers of lutein and $\beta$-carotene the next most abundant (Mendes-Pinto 2009). Carotenoids 
accumulate prior to veraison in the grape exocarp (skin) (Razungles et al. 1988, Guedes de Pinho et al. 2001). Although carotenoids and xanthophylls are concentrated in the skins of grapes, there is some dispute as to whether they are extracted into juice during winemaking. It was thought that carotenoids were too lipophilic to be extracted (Razungles et al. 1988), but more recent research has shown that they are present in Port musts and wines from the Douro Valley (Guedes de Pinho et al. 2001, Mendes-Pinto et al. 2005). This may be a function of the winemaking process where ethanol is added during the fermentation (with the exocarp present), potentially increasing the solubility of these compounds early in fermentation (Mendes-Pinto 2009).

Norisoprenoid formation from carotenoids. In 1970, the discovery of $\beta$-damascenone and $\beta$-damascone from Bulgarian rose oil (Rosa damascene) (Demole et al. 1970) initiated further investigation into norisoprenoid rose ketones. Rose ketones are a diverse group of aroma compounds possessing complex characters described as honey-like, flowery, and ionone-like depending on the concentration (Skouroumounis and Sefton 2002, Sefton et al. 2011). Of particular importance are the remarkably potent norisoprenoids, $\beta$-ionone (odor threshold in model wine, $0.09 \mu \mathrm{g} / \mathrm{L}$; Kotseridis et al. 1999 ) and $\beta$-damascenone (odor threshold in $10 \%$ ethanol, $0.05 \mu \mathrm{g} / \mathrm{L}$; Guth 1997b). Additional important aroma active norisoprenoids in wine include 1,1,6-trimethyl-1,2-dihydronaphthalene (TDN), associated with the kerosene bottle-aged character of Riesling wines (Simpson 1979, Winterhalter et al. 1990b), and (E)-1-(2,3,6-trimethylphenyl)buta-1,3-diene (TPB), which may be associated with the floral, geranium, and tobacco characters of aged Semillon wines (Janusz et al. 2003, Cox et al. 2005).

The formation of norisoprenoids is thought to occur from the biodegradation of the parent carotenoid, followed by enzymatic conversion to the aroma precursor (e.g., a glycosylated or other polar intermediate), and finally the acid-catalyzed conversion to the aroma-active compound (Winterhalter and Rouseff 2002). Once formed, these compounds are then subject to further acid reaction during wine aging (Skouroumounis and Sefton 2000). The specific enzyme systems involved in the initial biodegradation and oxidative cleavage of carotenoids to form norisoprenoids in grapes were hypothesized in the 1990s and later (Razungles et al. 1993, Baumes et al. 2002, Winterhalter and Rouseff 2002) but have only recently been described in $V$. vinifera (Mathieu et al. 2005). These carotenoid cleavage dioxygenase (CCD) enzymes cleave the $\mathrm{C}_{40}$ carotenoids mainly at the 9,10 and 9'10' double bonds. Four subfamilies have been identified-CCD1, CCD4, CCD7, and CCD8 - and cleavage may be symmetric or asymmetric depending on the enzyme and carotenoid substrate (Auldridge et al. 2006, Walter et al. 2010, Young et al. 2012). Recently, studies in Crocus sativa, rice, and mycorrhizal roots of Medicago truncatula indicate that CCD4 and CCD7 may be localized in the plastid and the $\mathrm{C}_{13}$ - and $\mathrm{C}_{27}$-apocarotenoids obtained from carotenoid cleavage are exported to the cytosol where further cleavage by CCD1 occurs, yielding $\mathrm{C}_{13^{-}}$and $\mathrm{C}_{14}$-apocarotenoid products (Floss et al. 2008, Rubio et al.
2008, Ilg et al. 2010). CCD7 and CCD8 are thought to be involved in formation of strigolactone, a plant hormone that inhibits shoot branching (Ruyter-Spira et al. 2013). The reported increase in expression of a CCD4 gene after veraison is suggestive of a role for this enzyme late in berry ripening (Guillaumie et al. 2011, Young et al. 2012).

Further research into this area is clearly required to better understand how the complement of CCD enzymes works in vivo. In addition, a recent study has also observed that grape cell cultures were able to metabolize the $\mathrm{C}_{13}$-norisoprenoids $\beta$-ionone and dehydrovomifoliol to secondary norisoprenoid volatiles, indicating that hydroxylases, oxidoreductases, and glycosyltransferases, yet to be identified, may also be critical in the biotransformation of these carotenoid cleavage products (Mathieu et al. 2009).

\section{Phenylpropanoids}

The biosynthesis of volatile phenylpropanoids has not been studied extensively in grapes, although a number of organand species-specific dehydrogenases, reductases, methyltransferases, and acetyltransferases that are involved in the biosynthesis of volatile phenylpropanoids have been identified in other plant systems (Dudareva et al. 2004, Dudareva and Pichersky 2006, Vogt 2010, Qualley et al. 2012). Still, little is known about the complete biosynthetic pathways leading to their formation in plants (Dudareva and Pichersky 2006). For example, while volatile phenylpropanoids, such as phenylethanol, phenylacetaldehde, benzaldehyde, and benzylacetate, are generally thought to be derived from L-phenylalanine, which is formed through the shikimic acid pathway in plastids, an alternative pathway through phenyl pyruvate has recently been suggested (Orlova et al. 2006). The phenylpropanoid pathway also leads to the formation of other important secondary metabolites in grapes, including hydroxycinnamates, stilbenes, lignin, lignan, aurones, flavones, isoflavonoids, as well as flavonoids, which include flavonols, tannins, and anthocyanins (Downey et al. 2006, Singh et al. 2010). The flavonoids are particularly important to the mouthfeel properties of red wines (Gawel 1998).

The phenolic content of wine is dependent, first, on grape phenolic content, which is influenced by a number of factors, including variety (Harbertson et al. 2008), grape maturity (Kennedy et al. 2002), variations in water and nutrient availability, light and temperature environment, and changes in predation and disease pressures (Downey et al. 2006, Cohen and Kennedy 2010). Second, it is based on the extractability of grape phenolics, which is influenced by interactions with cell wall material (Bindon et al. 2010) and numerous red winemaking practices (Sacchi et al. 2005). It is likely that similar variables will influence the volatile phenylpropanoid content of wines.

Volatile phenylpropanoids deserve significant consideration because of their observed abundance in hydrolyzates of glycoside isolates from juices and wines; for example, they can constitute 10 to $20 \%$ of the total hydrolyzed volatile fraction in Chardonnay juice (Sefton et al. 1993) and 51\% of the total hydrolyzed fraction in Tannat wine (Boido et 
al. 2003). They have been shown to contribute significantly to the dried fig, tobacco, and chocolate aromas in Cabernet Sauvignon and Merlot musts (Francis et al. 1998). One of the more interesting grape-derived volatile phenylpropanoids is methyl anthranilate, which is considered to be responsible for the distinctive "foxy" aroma and flavor of the Washington Concord grape (Vitis labrusca) (Wang and De Luca 2005) and may also contribute to the aroma of Pinot noir (Moio and Etievant 1995). First identified in grape juice in 1921 (Power and Chesnut 1921), methyl anthranilate has become a major compound used in the fragrance of perfumes and cosmetics and it is the chief grape flavor compound in food, used extensively in the flavoring of soft drinks and powder drinks (Wang and De Luca 2005).

It is also understood that volatile phenylpropanoids exist in wines through contact with other external sources. The most commonly recognized source is from oak (Quercus sp.) barrels used for fermentation and wine aging/storage (Spillman et al. 2004a, 2004b, Prida and Chatonnet 2010). Over 50 volatile phenylpropanoids have been identified in the smoke from pyrolyzed (toasted) oak (Guillén and Manzanos 2002). More recently, it has been established that various phenylpropanoids can be passed onto grapes through exposure to smoke events in the field (Kennison et al. 2007, 2008, Hayasaka et al. 2010), and these phenylpropanoids can also be released from nonvolatile complexes in grape juices and wines (Kennison et al. 2008, Hayasaka et al. 2010).

Saccharomyces cerevisiae metabolize aromatic amino acids, including phenylalanine and tyrosine, to produce substituted phenylpropanoids such as phenylethyl alcohol and 2-phenylethyl acetate (Rossouw et al. 2008, 2009). These compounds, with rose-like, floral, and honey aromas, are considered to play an important role in white wine aroma, as they are typically found at concentrations above odor threshold (Guth 1997a, López et al. 2003). Brettanomyces sp. and its ascosporogenous form Dekkera are well recognized for contributing to the volatile phenylpropanoid content of wines by breaking down hydroxycinammic acids to vinyl phenols and subsequently to ethyl phenols; the ethyl phenols are considered detrimental to consumer acceptability of wine, contributing leather and barnyard characters to the wine (Chatonnet et al. 1992, Lattey et al. 2010, Wedral et al. 2010). Brettanomyces and Dekkera yeast have a phenolic acid decarboxylase enzyme that converts hydroxycinnamic acids to their vinyl derivatives, which are the substrates of a second enzyme, vinylphenol reductase, whose activity results in the formation of ethylphenols (Harris et al. 2008). Many bacteria, fungi, and yeast have vinylphenol reductase activity, but under enological conditions it is predominantly Brettanomyces and Dekkera yeast that produce ethylphenols (Chatonnet et al. 1993, Suárez et al. 2007). Other studies have identified a number of lactic acid bacteria that are capable of decarboxylating phenolic acids to vinyl phenols while very few contain enzymes that are capable of forming ethyl phenols (Chatonnet et al. 1995, Couto et al. 2006).

Collectively, volatile phenylpropanoids and benzenoids are a diverse group of volatile compounds contributed from a range of sources and they can make significant contributions to wine aroma.

\section{Furan Derivatives and Furanones}

Furan derivatives, including furfural and 5-methylfurfural, are formed from pyrolysis of carbohydrates during oak wood toasting (and thus extracted into wines during barrel storage) (Guillén and Manzanos 2002) or from Maillard reactions during heating of grapes and wines (Cutzach et al. 1997, 1999). The furfurals contribute toasty and caramel aromas to wine, increasing the overall perception of oak intensity, irrespective of their low odor-activity values (Prida and Chatonnet 2010). The concentration of furans in wine, originating from oak, is dependent on the degree of toasting and oak surface area; oak species and seasoning also have varied and limited influence (Chatonnet et al. 1999, Cadahía et al. 2003, GardeCerdan and Ancin-Azpilicueta 2006, Fernández de Simón et al. 2010a, 2010b).

Sotolon (3-hydroxy-4,5-dimethylfuran-2(5H)-one), a chiral furanone, is responsible for the premature aging flavor in dry white wines (Pons et al. 2010). It is formed via oxidative degradation of ascorbic acid that may be added as an antioxidant to some wines prior to aging. The intermediate in this reaction, 2-ketobutyric acid, is also produced during alcoholic fermentation, and reaction of the keto acid with acetaldehyde may explain the presence of sotolon in wines even when ascorbic acid is not added (Pons et al. 2010).

Furan derivatives have also been observed to play important roles in the aroma of a number of fruits, including strawberry (Fragaria $\times$ ananassa) (Schieberle and Hofmann 1997), blackberry (Rubus L. subgenus Rubus and Rubus laciniatus) (Klesk and Qian 2003, Du et al. 2010), raspberry (Rubus idaeus) (Klesk et al. 2004), guava (Psidium guajava) (Steinhaus et al. 2009), and pineapple (Ananas comosus) (Tokitomo et al. 2005). One of the more important compounds in these studies, furaneol, was first identified in wines by Rapp and colleagues (Rapp et al. 1980) and has been identified in Vitis hybrid varieties (e.g., Baco and Villard noir), V. lambr$u s c a$ varieties (e.g., Noah and Isabella), and $V$. vinifera varieites (e.g., Carignan and Gewürztraminer) (Guedes de Pinho and Bertrand 1995, Ong and Acree 1999). A recent study of Italian $V$. vinifera varieties (Genovese et al. 2005) has also suggested that furaneol is important to the aroma of Refosco and Primitivo (also known as Zinfandel in the United States and Crljenak kaštelanski or Pribidrag in Croatia; Maletić et al. 2004). Both furaneol and homofuraneol have low odor thresholds, 5 and $125 \mu \mathrm{g} / \mathrm{L}$, respectively, and have an additive and/or synergistic role in conveying the fruity and caramel character of rosé wines (Ferreira et al. 2002, Masson and Schneider 2009). Furaneol biosynthesis has been studied in strawberry and key enzymes have been identified (Raab et al. 2006, Schiefner et al. 2013); however, formation mechanisms in grapes and wine are unknown.

The furanones are clearly important contributors to wine aroma and have origins from both oak and fruit. However, further research on the chemical and biochemical origins of these compounds is necessary in order to better understand 
the factors that influence the concentrations and the diversity of these compounds in wine.

\section{Fatty Acid Derivatives}

In plants, a number of straight-chain alcohols, aldehydes, ketones, acids, esters, and lactones are derived from fatty acids via $\alpha$ - or $\beta$-oxidation or through the lipoxygenase pathway (Schwab et al. 2008). The major aroma compounds derived from fatty acids in grapes tend to be the $\mathrm{C}_{6}$-aldehydes and alcohols (Ferreira et al. 1995, Dunlevy et al. 2009, Iyer et al. 2010), many of which are thought to be responsible for "green" aromas in grape juice, although they may have less of an impact in wines (Kotseridis and Baumes 2000). The $\mathrm{C}_{6}$ compounds are generally formed by the action of grapederived lipoxygenase (LOX), hydroperoxide lyase (HPL), (3Z)-(2E) enal isomerase, and alcohol dehydrogenase (ADH) enzymes that are synthesized, activated, and/or released from compartments separate from their substrates when the grape is crushed (Schwab et al. 2008). These $\mathrm{C}_{6}$ compounds can also act as substrates for ester production by yeast during fermentation (Keyzers and Boss 2010, Dennis et al. 2012).

The other major grape-derived compounds with a fatty acid origin are the $\gamma-(4)$ and $\delta$-(5) lactones that are derived from the corresponding 4- or 5-hydroxy carboxylic acids. The enzymes involved in synthesis of these compounds have not yet been determined in plants and, therefore, little is known about their formation in grapes (Schwab et al. 2008). $\delta$-Lactones are generally discounted in importance compared to the $\gamma$-lactones, which tend to have odor thresholds an order of magnitude lower for compounds of a similar molecular weight (Ferreira et al. 2000). Both $\gamma$ - and $\delta$-lactones have been identified in wine. However, their contribution to wine aroma has yet to be confirmed. One recent study suggests that, although no single $\gamma$-lactone was found at concentrations above its odor threshold, the lactones in combination may contribute to the aroma of wine through synergistic effects (Cooke et al. 2009). In contrast, a separate study correlated $\gamma$-nonalactone levels with prune-like aromas in aged red wine (Pons et al. 2008), and numerous studies have correlated $\gamma$ - and $\delta$-lactones with the aroma of botrytized wines from Sauternes (Bailly et al. 2009), Barsac, Loupiac (Sarrazin et al. 2007a), Campania (sweet Fiano wines) (Genovese et al. 2007), and Hungary (Tokaji Aszú) (Miklósy and Kerényi 2004). As less is known about the origins of fatty acid derivatives compared to other grape-derived volatile compounds, further research is warranted to better understand their formation and contribution to wine aroma.

\section{Sugar and Amino Acid-Derived Volatile Acids, Esters, and Higher Alcohols}

It is well understood that yeast- and bacteria-derived volatile metabolites, which include volatile fatty acids, esters, higher alcohols, and carbonyls, are produced through sugar and amino acid metabolism (Swiegers et al. 2005a). Many of these compounds can be produced by plants (Schwab et al. 2008), but wine research has focused on the contribution of microflora since the majority of volatile fatty acids, esters, and higher alcohols are absent in grape must and are produced during the fermentation process (Bell and Henschke 2005, Swiegers et al. 2005a, Sumby et al. 2010, Cordente et al. 2012).

Fatty acids. Yeasts produce short-, medium-, and longchain fatty acids, with the short- ( $<6$ carbons) and medium- $(6$ to 12 carbons) chain fatty acids comprising the volatile fatty acids. The majority of fatty acids produced by yeast are of the long-chain type (>12 carbons), such as palmitic (C16) and stearic (C18) acids (Tehlivets et al. 2007). However, these are too large and nonvolatile to contribute to the aroma of wine. The short-chain fatty acid acetic acid (C2) accounts for $>90 \%$ of the volatile fatty acids in wine and is formed as a metabolic intermediate in the synthesis of acetyl-CoA from pyruvic acid (Bell and Henschke 2005).

Short-chain fatty acids that potentially contribute to wine flavor include the branched-chain isobutyric and isovaleric and the straight-chained butyric, and propanoic acids (Francis and Newton 2005), but the role these compounds play in wine sensory characteristics has not been studied extensively. Isobutyric and isovaleric acids have been noted as markers of Brettanomyces bruxellensis spoilage and are thought to be capable of masking the "Brett character" attributed to 4-ethylphenol and 4-ethylguaiacol, which is somewhat counter-intuitive (Romano et al. 2009), since the short-chain fatty acids have sweaty, cheesy-like aromas (Francis and Newton 2005).

The medium-chain fatty acids, hexanoic (C6), octanoic (C8), and decanoic (10), also contribute to wine aroma (Francis and Newton 2005), and their concentrations are dependent on anaerobic growth conditions, must composition, grape cultivar, yeast strain, fermentation temperature, and winemaking practices (Edwards et al. 1990, Bardi et al. 1999). Mediumchain fatty acids are correlated with stuck and sluggish fermentations, as they are inhibitory to S. cerevisiae and to some bacteria (Bisson 1999). The inhibitory effect of medium-chain fatty acids usually occurs under conditions of low $\mathrm{pH}$, low temperature, and high ethanol concentrations (Viegas and SáCorreia 1995, 1997). However, another study has suggested that cell growth is arrested because fatty acid biosynthesis is prevented by the lack of oxygen and that elevated mediumchain fatty acids are not the primary cause of stuck fermentation (Bardi et al. 1999).

Esters. Esters represent the greatest concentration of volatile compounds in alcoholic beverages (Mason and Dufour 2000), and they contribute to and enhance sweet-fruity aromas in wines. For example, in Bordeaux red wines, higher than average levels of ethyl propanoate, ethyl 2-methylpropanoate, and ethyl 2-methylbutanoate were involved in blackberry aromas, while ethyl butanoate, ethyl hexanoate, ethyl octanoate, and ethyl 3-hydroxybutanoate conferred red berry aromas (Pineau et al. 2009). In addition, phenylpropanoid esters, including ethyl cinnamate, ethyl dihydrocinnamate, and 2-phenylethyl acetate in combination with linalool have been noted to enhance ripe fruit, honey, and sweet characters in neutral red wines (Escudero et al. 2007).

The most important esters and acetates in wine are considered to be the fatty acid ethyl esters and acetates, including ethyl acetate, ethyl butyrate, ethyl hexanoate, ethyl octanoate, 
ethyl decanoate, hexyl acetate, isoamyl acetate, isobutyl acetate, and phenylethyl acetate (Guth 1997a, Ferreira et al. 2000, Francis and Newton 2005, Swiegers et al. 2005a). In general, most of the ethyl esters and acetates are present at similar or higher concentrations in white wines compared to red wines (Guth 1997b, Ferreira et al. 2000, Francis and Newton 2005). Esters are generally considered to be products of yeast metabolism through lipid and acetyl-CoA metabolism (Swiegers et al. 2005a). Acetate ester formation by S. cerevisiae is catalyzed by alcohol acetyl transferases I and II (AATase I and II) from two substrates, an alcohol and acetyl-CoA (Saerens et al. 2010). Although the substrate concentrations are important to acetate formation, it has been observed that the expression levels of the alcohol acetyltransferases $A T F 1$ and $A T F 2$ are the most important factor in determining the acetate ester levels during fermentation (Verstrepen et al. 2003b).

In contrast, for ethyl esters it has been observed that fatty acid precursor levels are the major factor limiting production, rather than the activity of the biosynthetic enzymes (Saerens et al. 2008). Ethyl ester formation by $S$. cerevisiae is catalyzed by at least two acyl-CoA:ethanol $O$-acyltransferases (AEATases), EEB1 and EHT1 (Saerens et al. 2006, 2010). The medium-chain fatty acid ethyl esters are the product of an enzyme-catalyzed condensation reaction between an acylCoA component and ethanol (Saerens et al. 2010). Esters can also be produced through bacterial metabolism and chemical modifications. For example, ethyl lactate is known to be directly linked to the concentration of lactic acid produced through malolactic fermentation (de Revel et al. 1999, PozoBayón et al. 2005, Boido et al. 2009).

During fermentation, the formation of acetate and ethyl esters is considerably reduced by the presence of dissolved oxygen and unsaturated fatty acids in wine (Mason and Dufour 2000, Saerens et al. 2010). The reduced formation of acetate esters is primarily due to the nullified induction of a low-oxygen response element (LORE) in the alcohol acetyl transferase gene $A T F 1$ promoter sequence (Mason and Dufour 2000, Verstrepen et al. 2003a). Conversely, reductions in ethyl esters are primarily thought to be due to the availability of medium-chain fatty acid precursors and not to the expression of EEB1 and EHT1 (Saerens et al. 2008).

A number of studies have observed changes in ester concentrations in wines during maturation and storage. In general, the loss of fruity and floral aromas in young white wine during storage is associated with the hydrolytic loss of acetates and esters (Marais and Pool 1980, Ramey and Ough 1980, Pérez-Coello et al. 2003), with similar results observed in red wines (Ough 1985). Cooler storage temperatures (0 and $10^{\circ} \mathrm{C}$ ) result in less hydrolysis and retention of the fruity aromas of young wines (Marais and Pool 1980). In a recent study, there was a decrease in concentrations of ethyl esters and acetates during uncontrolled storage conditions and times $(1,2,3$, and 4 years and recently bottled wines) (Pérez-Coello et al. 2003).

Alcohols. Saccharomyces cerevisiae produces the majority of higher alcohols from sugar metabolism, producing $\alpha$-keto acid precursors from pyruvate and acetyl-CoA via the tricarboxylic acid (TCA) cycle (Crowell et al. 1961, Bell and Henschke 2005, Swiegers et al. 2005a). Alternatively, higher alcohols are produced when the yeast catabolize amino acids via the Ehrlich pathway (Bell and Henschke 2005, Swiegers et al. 2005a). Via this pathway, the amino acids are completely consumed during the early yeast growth phase, resulting in production of the corresponding higher alcohols later during the yeast stationary phase (Bell and Henschke 2005, LópezRituerto et al. 2010).

The branched-chain higher alcohols, including isoam$\mathrm{yl}$ alcohol and isobutyl alcohol, are synthesized from the branched-chain amino acids and have whiskey/malt/burnt and wine/solvent/bitter aromas, respectively (Francis and Newton 2005). The aromatic amino acids, including phenylalanine and tyrosine, produce aromatic alcohols, such as phenylethyl alcohol (Rossouw et al. 2008, 2009), which has a honey/spice/ rose/lilac aroma (Francis and Newton 2005). As discussed previously, phenylethyl alcohol is considered to play an important role in white wine aroma, as it is typically found at concentrations above an odor threshold of $10 \mathrm{mg} / \mathrm{L}$ (Guth 1997a, López et al. 2003).

Production of fermentation-derived volatiles. Nitrogen plays an important role in the formation of volatile fatty acids, esters, and higher alcohols, and both the concentration and speciation of assimilable nitrogen in the must is important in defining the volatile metabolites produced by yeast (Hernández-Orte et al. 2002, 2005, Miller et al. 2007). Since these nitrogenous substrates are predominantly grape-derived, the production of yeast-derived volatiles is dependent on, or modulated by, the initial grape nitrogenous composition. This is consistent with increased levels of higher alcohols and esters produced during fermentation of grapes with high levels of available nitrogen as a result of being grown in nitrogensupplemented vineyard soils (Bell and Henschke 2005).

Fermentation temperature also plays an important role in the formation of yeast-derived volatile compounds (Molina et al. 2007) and has an influence on the sensory characteristics of both white and red wines (Reynolds et al. 2001). Finally, there have also been a number of studies that have indicated that different yeast strains (and the corresponding genetic differences) influence the volatile composition and subsequently the aroma of wine (Miller et al. 2007, Torrens et al. 2008, Bisson and Karpel 2010, Callejon et al. 2010, King et al. 2011, Robinson et al. 2011, Richter et al. 2013).

Clearly this is a complex area of research that explores elements of grape composition in defining what is available for yeast metabolism, while at the same time assessing how fermentation conditions such as temperature, and yeast genetics, and metabolism define the complement of fermentation volatiles. Recent studies suggest that there are pools of grape precursors that influence the products formed by yeast metabolism and/or grape-derived modulators of yeast biochemical activities that can influence wine volatile composition (Keyzers and Boss 2010, Dennis et al. 2012). Future research in this field will benefit from defining not only the factors that influence precursor levels in the grapes but also the factors that influence yeast biochemical activity. This information will aid 
in understanding the critical operational points available to manipulate wine composition in the vineyard and the winery.

\section{Pyrazines}

The 3-alkyl-2-methoxypyrazines, including 3-isobutyl2-methoxypyrazine (IBMP), 3-isopropyl-2-methoxypyrazine (IPMP), and sec-butyl-2-methoxypyrazine (SBMP), impart sensory characteristics of bell pepper, asparagus, or pea (Sala et al. 2000) to wines and are detectable at ng/L concentrations (Kotseridis et al. 1998). Initially identified in bell pepper (Capsicum annum var. grossum) (Buttery et al. 1969), these green-flavored pyrazines also occur in chili peppers (Capsicum annuum var. annuum) (Mazida et al. 2005), pea (Pisum sativum) (Jakobsen et al. 1998), potato (Solanum tuberosum) (Oruna-Concha et al. 2001), and cheese (Neta et al. 2008). Although analytical detection of these compounds at such low concentrations has made their investigation difficult, it is now common knowledge that methoxypyrazines play an important role in the aroma of both the juice and wine of Sauvignon blanc (Allen et al. 1991, Lacey et al. 1991), Cabernet Sauvignon (Allen et al. 1990, 1994), Cabernet franc (Roujou de Boubée et al. 2000), Merlot (Sala et al. 2000), and Carmenere (Belancic and Agosin 2007). Low levels of methoxypyrazines contribute to varietal character of these wines and are desired for some wine styles; however, high levels are generally considered undesirable. Methoxypyrazines have been found at levels below their odor threshold in unripe Pinot noir, Chardonnay, and Riesling, but it is unclear if that is due to other tissues such as stems and tendrils being present during crushing and extraction (Hashizume and Samuta 1999).

It has been suggested that that the enzymatic methylation of hydroxypyrazine precursors to methoxypyrazines by $O$ methyltransferases (OMT) is an important factor in determining the level of methoxypyrazine accumulation in grape berries (Hashizume et al. 2001, Dunlevy et al. 2010). Putative genes, including $V v O M T 1$ and $V v O M T 3$, that encode enzymes capable of methylating hydroxypyrazines have been identified in Cabernet Sauvignon grape berries (Dunlevy et al. 2010, 2013, Vallarino et al. 2011, Guillaumie et al. 2013). The VvOMT3 gene in particular has a high affinity for the isobutyl hydroxypyrazine substrate and has been found in berries of other varieties known to have high levels of IBMP, including Cabernet franc, Sauvignon blanc, Merlot, Semillon, Fer, Ruby Cabernet, and Roussane (Dunlevy et al. 2013). Gene expression was highest between 4 and 8 weeks postflowering and declined to lower levels postveraison (Dunlevy et al. 2010, 2013), coinciding with the accumulation of methoxypyrazines in these berries. Although methoxypyrazines occur in other grapevine tissues, including the rachis (bunch stem), flowers, tendrils and roots, but not the leaves (Dunlevy et al. 2010), they are not translocated from these tissues to the fruit (Koch et al. 2010).

Research has indicated that the content of alkyl methoxypyrazines in the wine depends primarily on grape composition (Roujou de Boubée et al. 2002). Therefore, most studies have addressed the management of alkyl methoxypyrazines through viticultural practices (Chapman et al. 2004,
Sala et al. 2004, Falcão et al. 2007), with particular emphasis on cluster light interception (Hashizume and Samuta 1999, Ryona et al. 2008). The exception to this proposition has been in the study of ladybug taint, which is the contribution of 3-isopropyl-2-methoxypyrazine (IPMP), extracted from Harmonia axyridis (Pallas) (Galvan et al. 2008), which can increase the peanut, asparagus/bell pepper, and earthy/herbaceous aromas in red wines (Pickering et al. 2004).

Pyrazines have been of particular interest to grape and wine researchers due to their low odor threshold and their correlation with herbaceous aromas in Cabernet Sauvignon and Sauvignon blanc, both abundantly planted and important grape varieties in the international market. Further research into understanding the formation of these compounds in grapes will lead to a better ability to manipulate their concentrations in wines for specific market segments.

\section{Volatile Sulfur Compounds}

Sulfur-containing volatile compounds were originally associated with malodors mainly due to molecules such as hydrogen sulfide $\left(\mathrm{H}_{2} \mathrm{~S}\right)$, methylmercaptan (methanthiol), ethanethiol, and methionol. However, that is no longer the case with the discovery of a number of volatile thiols that impart pleasant herbaceous, fruity, mineral, smoky, and toasty aromas in wine (Dubourdieu and Tominaga 2009). The most abundant volatile sulfur compounds in wines are $\mathrm{H}_{2} \mathrm{~S}$, methanthiol, dimethylmercaptans (dimethylsulfide, dimethyldisulfide, dimethyltrisulfide), methylthioesters $(S$ methyl thioacetate, $S$-methyl thiopropanoate, and $S$-methyl thiobutanoate), and liberated glutathione and cysteine polyfunctional thiols (4-mercapto-4-methylpentan-2-one, 4MMP; 3-mercaptohexan-1-ol, 3MH; and 3-mercaptohexyl acetate, 3MHA) (Swiegers and Pretorius 2007, Dubourdieu and Tominaga 2009, Roland et al. 2010). A myriad of other sulfur-containing compounds have been identified in wines, suggesting that there is still much to be discovered in this area (Mestres et al. 2000, 2002, Bailly et al. 2006, Sarrazin et al. 2007b, Dubourdieu and Tominaga 2009).

Hydrogen sulfide can be generated by $S$. cerevisiae through the degradation of sulfur-containing amino acids (cysteine and glutathione), the reduction of elemental sulfur, or the reduction of sulfite or sulfate (Rauhut and Körbel 1994, Rauhut 2009). Hydrogen sulfide production varies across yeast strains and with the nitrogen status of the juice (Acree et al. 1972, Schutz and Kunkee 1977, Giudici and Kunkee 1994, Rauhut et al. 1996, Jiranek et al. 1995, Sea et al. 1998, Bell and Henschke 2005, Linderholm et al. 2008, Kumar et al. 2010). It is generally understood that the addition of nitrogen, in the form of amino acids, with the exception of cysteine, or ammonium, reduces the production of $\mathrm{H}_{2} \mathrm{~S}$ by yeast. That is because these sources of nitrogen are precursors for $O$-acetylserine or $O$-acetylhomoserine synthesis, which are important in the synthesis of cysteine, methionine, and glutathione (Giudici and Kunkee 1994, Jiranek et al. 1995, Linderholm et al. 2008). The activity of $O$ acetylserine/ $O$-acetylhomoserine sulfhydrylase (the enzyme responsible for incorporating reduced sulfur into organic 
compounds) is not the only factor important for reducing $\mathrm{H}_{2} \mathrm{~S}$ production, but rather the activity of a complement of enzymes involved in the synthesis of $O$-acetyl-L-homoserine and homocysteine can help to reduce $\mathrm{H}_{2} \mathrm{~S}$ production in $S$. cerevisiae (Spiropoulos and Bisson 2000, Linderholm et al. 2008). Interestingly, a recent study indicates that the nutrients used during rehydration of yeasts for use in grape juice fermentations can influence formation of $\mathrm{H}_{2} \mathrm{~S}$ (and other volatiles) (Winter et al. 2011). In this study, kinetics of $\mathrm{H}_{2} \mathrm{~S}$ production were altered, but not expression of genes in the sulfate assimilation pathway. The authors note that manipulations to the yeast rehydration protocols may be a "potential approach for managing sulfur aroma compounds in wines" (Winter et al. 2011).

Methionine and cysteine are thought to be regulators of the sulfur reduction pathway. However, it is hypothesized that under the anaerobic conditions experienced during fermentation, cysteine concentrations may play a more important regulatory role in sulfate reduction (Linderholm et al. 2008). It has been shown that yeast respond to the addition of cysteine by increasing the production of $\mathrm{H}_{2} \mathrm{~S}$ in preference to methionol while the addition of methionine results in an increase in methionol in preference to $\mathrm{H}_{2} \mathrm{~S}$ (Moreira et al. 2002). This could be partly attributed to cysteine inhibiting serine $O$ acetyltransferase, which lowers the cellular concentration of $O$-acetylserine required for induction of the sulfate reduction pathway (Ono et al. 1996, 1999), and/or cysteine repressing the genes which encode cystathionine $\beta$-synthase and cystathionine $\gamma$-lyase in addition to the genes involved in the sulfate reduction pathway (Hansen and Francke Johannesen 2000). A number of other volatile sulfur compounds can be formed from reactions of $\mathrm{H}_{2} \mathrm{~S}$ with other organic compounds; for example, $\mathrm{H}_{2} \mathrm{~S}$ in combination with ethanol or acetaldehyde forms ethanethiol (Swiegers et al. 2005a).

Dimethylsulfide (DMS) is thought to be formed from microbial degradation of methionine and cysteine, although definitive pathways in wine fermentations have not been demonstrated (Anness and Bamforth 1982, de Mora et al. 1986). Dimethylsulfide has been noted to increase black olive, truffle, and undergrowth sensory attributes in Syrah wines (Segurel et al. 2004) and can also enhance the fruit aroma of red wines as a result of complex interactions with other volatile compounds, including esters and norisoprenoids (Segurel et al. 2004, Escudero et al. 2007). However, DMS is generally not considered to contribute positively to white wine aroma since it enhances asparagus, corn, and molasses characters, although this could be considered as increasing the complexity of the aroma (Goniak and Noble 1987). DMS, methionol, diethyl sulfide, and diethyl disulfide increase in wine with age and with increased temperature and may contribute to the aroma of aged wines (Marais 1979, Simpson 1979, Fedrizzi et al. 2007).

Methionol contributes to the raw potato or cauliflower character of wines, can be found in wines at concentrations up to $5 \mathrm{mg} / \mathrm{L}$, and is produced by either $S$. cerevisiae or Oenococcus oeni through the catabolism of methionine (Moreira et al. 2002, Ugliano and Moio 2005, Vallet et al.
$2008,2009)$. It contributes to the cooked vegetable aroma of oxidized wines (Escudero et al. 2000). Methional concentrations increase in white wines exposed to elevated temperatures and oxygen. Under these conditions, the compound is produced via a Strecker degradation of methionine to methional in the presence of a dicarbonyl compound or via direct peroxidation of methionol (Escudero et al. 2000, Silva Ferreira et al. 2002).

Much research interest has focused more recently on a group of sulfur-containing compounds referred to as the polyfunctional thiols, which impart pleasant fruity aromas to a range of varieties, including Scheurebe, Sauvignon blanc, Gewürztraminer, Riesling, Colombard, Petit Manseng, Semillon, Cabernet Sauvignon, and Merlot (Darriet et al. 1995, Guth 1997b, Tominaga et al. 1998, 2000a, Murat et al. 2001, Peña-Gallego et al. 2012). Polyfunctional thiols are thought to be important to the varietal characteristics of wine aroma and are noted for low odor thresholds, with 4MMP, 3MH, and 3MHA detectable in wine at concentrations of ng/L (Tominaga et al. 1998, 2000a, Francis and Newton 2005, Swiegers et al. 2005a, Swiegers and Pretorius 2007, Dubourdieu and Tominaga 2009).

For over 10 years after they were initially identified, the thiols were thought to be formed from the cysteine conjugates. It has been shown more recently that glutathione precursors are an equally, if not more important, source of these pleasant smelling polyfunctional thiols (Subileau et al. 2008, Fedrizzi et al. 2009, Capone et al. 2010, Grant-Preece et al. 2010, Roland et al. 2010, Winter et al 2010). A recent study documented that the glutathione-conjugated $3 \mathrm{MH}$ diastereomers were up to 35 times more abundant than their cysteineconjugated counterparts in juices of Sauvignon blanc, Riesling, Chardonnay, and Pinot Grigio; Sauvignon blanc juices generally had the highest concentrations of the varieties studied (Capone et al. 2010).

The conjugated thiol precursors are produced in the grape and concentrations are highest in the skin (Roland et al. 2011), but little is known about the mechanisms involved in their biosynthesis. Recent work has shown that the glutathione moiety can be conjugated to the $\mathrm{C}_{6}$-aldehyde, $(E)$-2-hexenal, which is presumably reduced enzymatically to the alcohol by alcohol dehydrogenase (Capone and Jeffery 2011). The same group has also shown that grapes can contain 3-S-cysteinylglycinehexan-1-ol, an intermediate in the catabolism of the glutathione conjugate to the cysteine conjugate (Capone et al. 2011). One study assessed the cysteine-conjugated precursors of 4MMP, 4-mercapto-4-methylpentan-2-ol (4MMPOH), and $3 \mathrm{MH}$ in Sauvignon blanc and determined that these precursors accumulate with increasing grape maturity (Perot des Gachons et al. 2000) and concentrations can vary with vineyard site (Perot des Gachons et al. 2005). Interestingly, differences in thiol levels associated with vineyard sites may contribute to the distinct regional style of New Zealand Marlborough wines (Benkwitz et al. 2012) as well as to differences in sensory styles from various sites within the Marlborough region (Benkwitz et al. 2012). However, more viticultural research should be conducted to improve our understanding 
of the formation of these conjugated polyfunctional thiols in grapes.

A main research focus has been on the release of polyfunctional thiols during fermentation, due primarily to the fact that yeasts have limited and varied capacity to liberate the polyfunctional thiols from their precursors (Subileau et al. 2008, Capone et al. 2010, Winter et al. 2011). For example, estimates from the literature vary from 0.1 to $12 \%$ conversion of cysteine-3MH to 3MH (and 3MHA) (Subileau et al. 2008), representing only a small fraction of the polyfunctional thiols present in juice and leaving significant pools of both cysteine and glutathione precursors in finished wines (Capone et al. 2010). It has been established that yeast strains having carbon-sulfur $\beta$-lyase activity release these polyfunctional thiols during fermentation (Howell et al. 2005, Swiegers et al. 2007, Ugliano 2009, Holt et al. 2011). As the level of carbon-sulfur $\beta$-lyase activity varies due to yeast strain, yeast selection can be used, in part, to control the polyfunctional thiol content of wine (Dubourdieu et al. 2006, Swiegers and Pretorius 2007, Roncoroni et al. 2011).

3-Mercaptohexan-1-ol decreases rapidly in red wines stored in barrel, as the compound oxidizes easily and is highly reactive with quinones (Dubourdieu and Tominaga 2009). Further, winemakers commonly use copper sulfate to remove $\mathrm{H}_{2} \mathrm{~S}$ from wines at the conclusion of fermentation or just before bottling, which has recently been noted to reduce $3 \mathrm{MH}$ in bottled Sauvignon blanc (Ugliano et al. 2010).

Comprehensive reviews of polyfunctional thiol chemistry and biochemistry have recently been published, focusing on viticultural, winemaking, and storage variables that influence the levels of these compounds in wines (Coetzee and du Toit 2012, Peña-Gallego et al. 2012). Future research into the longer-term stability of these polyfunctional thiol compounds and potential reactivity with additives and fining agents is warranted.

The sulfur-containing furans are another group of pleasant smelling thiols and include 2-methyl-3-furanthiol and 2-furanmethanethiol. These are formed during oak toasting and may contribute to the toasty and roast coffee aroma characteristics of oak-matured wines, including Sauvignon blanc, Chardonnay, Merlot, Cabernet franc, and Cabernet Sauvignon, and sweet Petit Manseng wines (Tominaga et al. 2000b, Tominaga and Dubourdieu 2006).

The volatile sulfur compounds are a diverse group of highly odor-active compounds with multiple influences contributing to their presence in wine. They clearly make an important contribution to wine aroma and given the number of sulfur compounds identified in wine over the last decade, there is potentially still much to be discovered in this area (Dubourdieu and Tominaga 2009).

\section{Glycosylated Aroma Precursors}

Glycosylated aroma precursors consist of a glycopyranosyl (sugar moiety) and an aglycone (nonsugar moiety) joined by a $\beta$-glycosidic linkage (Williams 1993). Glycosylated aroma precursors have been identified in almost 170 plants across nearly 50 families (Chassagne et al. 1998) and in a wide range of plant tissues including leaves, fruit, roots, petals, needles, woody tissues, and seeds (Winterhalter and Skouroumounis 1997). Plants produce a range of lipophilic secondary metabolites including cannabinoids, flavonoids, diterpene sclareol, alkaloids, benzoxazinones, phenylpropanoids, cyanogenic glycosides, and glucosinolates as a self-defense mechanism against pathogens and herbivores (Sirikantaramas et al. 2008). The glycosylation of these lipophilic aroma compounds and subsequently compartmentalization (Hardie et al. 1996) may act as a detoxification mechanism in plants (Sirikantaramas et al. 2008). The glycosylation of flavor compounds is thought to increase the water solubility of the aglycone to improve storage in vacuoles (Hardie et al. 1996) and transport within the plant (Winterhalter and Skouroumounis 1997, Sirikantaramas et al. 2008). However, terpene alcohols and phenols do not always change in solubility due to the glycosylation of their hydroxyl groups (Stahl-Biskup et al. 1993).

Several reviews have dealt with the field of glycosylated aroma precursors in grapevine (Günata et al. 1993, StahlBiskup et al. 1993, Williams 1993, Winterhalter and Skouroumounis 1997). Commonly in grapes, a disaccharide forms with either $\alpha$-L-arabinofuranosyl, $\alpha$-L-rhamnopyranosyl, $\beta$-Dxylopyranosyl, $\beta$-D-apiofuranosyl, or $\beta$-D-glucopyranosyl linked to position 6 of the glucose (Williams 1993). This is of particular interest since all anthocyanin glycosides are found as monoglycosides in $V$. vinifera (Ribéreau-Gayon 1974), suggesting that aroma compound glycosylation occurs via specific pathways separate from those which glycosylate anthocyanins. In addition, glycoconjugated terpenes and norisoprenoids in the grape are synthesized independently of those produced in the leaves in Shiraz and Muscat of Alexandria (Gholami et al. 1995, Günata et al. 2002), indicating that glycosylated aroma precursors are synthesized de novo and not translocated to the fruit from other plant tissues.

These previous studies point to the importance of future research aimed at a functional characterization of glycosyltransferases responsible for the biosynthesis of aroma precursors. A diverse array of glycosyltransferases has already been identified in other plant species (Lairson et al. 2008). For example, glycosyltransferases in Medicago truncatula have been shown to be capable of glycosylating both flavonoids and triterpenes (Shao et al. 2005), those of Arabidopsis thaliana have been shown to have activity toward mono-, sesqui-, and diterpenes in vitro (Caputi et al. 2008), and, recently, those identified in Valencia orange (Citrus sinensis L. Osbeck) were shown to be capable of glucosylating terpenoids in leaf, flower, and fruit tissues (Fan et al. 2010). It is probable that grape glycosyltransferases are likely to have similar properties and various enzymes have been identified that appear to be involved in the production of grape flavonoid glycosides (Offen et al. 2006, Ono et al. 2010). However, to date, there is no information regarding enzymes involved in the synthesis of glycosylated aroma precursors in grape (Baumes et al. 2002, Mathieu et al. 2009).

Glycosidically bound aroma compounds are an important reserve of aroma in wine (Williams 1993). This flavor reserve either evolves over time because of slow acid hydrolysis 
(Skouroumounis and Sefton 2002) or can be released by the application of exogenous fungal glycosidases (Günata et al. 1993). For example, the norisoprenoids 1,1,6-trimethyl-1,2-dihydronaphthalene (TDN) and vitispirane isomers derive from glycosidic precursors (Winterhalter et al. 1990b, Winterhalter 1991, Full and Winterhalter 1994) and are typically found in Riesling wines that have been bottle aged (Simpson 1979) and/or heated (Simpson 1978, Silva Ferreira and Guedes de Pinho 2004). Endogenous grape-derived glycosidases (Aryan et al. 1987, Günata et al. 1990), exogenous yeast-derived glycosidases (Günata et al. 1986, Zoecklein et al. 1997, Ugliano et al. 2006), and bacterial glucosidases (Grimaldi et al. 2005a, $2005 \mathrm{~b}$ ) are also considered to play an important role in the release of these aroma precursors in wine but not in the fruit, presumably due to glucose inhibition (Günata et al. 1993) or compartmentation.

Grape-derived glycosidase enzymes are located in the pulp and juice fraction (Aryan et al. 1987) and they have characteristics similar to those of $S$. cerevisiae. The activity of Saccharomyces-derived $\beta$-glucosidases, $\alpha$-rhamnosidases, and $\alpha$-arabinosidases increases during the exponential yeast growth phase (first 24 hours of fermentation) and rapidly decreases over the following three days (Delcroix et al. 1994). Glycosidase activity is subject to the influence of $\mathrm{pH}$, temperature, and the presence of ethanol, glucose, phenols, polyphenols, and cations (Günata et al. 1993). Consequently, the impact of glycosidases on the release of aroma molecules from precursors is dependent on the stability and activity of these enzymes in the juice or wine medium. The yeast intracellular $\mathrm{pH}(5.0$ to 6.0$)$ is highly favorable to yeast glycosidase stability (Delcroix et al. 1994). In contrast the activity of $S$. cerevisiae $\beta$-glycosidase is reduced by $90 \%$ at $\mathrm{pH} 3.0$ (similar to juice or wine $\mathrm{pH}$ ) after 90 minutes (Günata et al. 1993). This reduced activity has also been observed in grape-derived $\beta$-glycosidase (Aryan et al. 1987). In contrast, $\beta$-glucosidase found in Debaryomyces hansenii has been observed to have a similar activity to that of Saccharomyces glycosidase, except it is stable at wine $\mathrm{pH}$ (Yanai and Sato 1999). Further, $\beta$-glycosidases derived from Aspergillus niger, commonly associated with Botrytis cinerea bunch rot (Nair 1985, Zahavi et al. 2000, Hocking et al. 2007), lose only $20 \%$ of their activity under similar conditions, suggesting they too are relatively stable at juice and wine pH (Günata et al. 1993).

Temperature plays an important role in the activity of enzymes due to reaction kinetics and enzyme stability. The maximum activity of $S$. cerevisiae-derived $\beta$-glycosidases occurs at temperatures of 40 to $50^{\circ} \mathrm{C}$ (Delcroix et al. 1994), which is similar to the results reported for the A. niger enzymes (Günata et al. 1993). Importantly, the activity of these enzymes is relatively low at $30^{\circ} \mathrm{C}(\sim 10$ to $15 \%$ of maximum) and rapidly increases as temperatures approach $60^{\circ} \mathrm{C}(\mathrm{Del}-$ croix et al. 1994). Consequently, hydrolysis of glycosides by $\beta$-glycosides is likely to be slow during fermentation and wine storage due to the low temperatures $\left(10\right.$ to $20^{\circ} \mathrm{C}$ ).

Ethanol has been observed to significantly reduce the activity of $\beta$-glycosidase derived from grape leaves, grapes, and almond emulsin (Aryan et al. 1987). However, $\beta$-glycosidases derived from S. cerevisiae (Delcroix et al. 1994) and A. niger (Aryan et al. 1987) have shown losses of only $10 \%$ and $20 \%$ activity, respectively, at concentrations of $15 \%$ ethanol.

The activity of $\beta$-glycosidase is usually competitively inhibited by the presence of glucose. It is interesting to note that the activity of $S$. cerevisiae-derived $\beta$-glucosidase is only reduced $\sim 20$ to $30 \%$ at glucose concentrations typically found in juice (Günata et al. 1993, Delcroix et al. 1994). The variation in reported activity is likely due to variations in experimental conditions such as glucose concentration. In contrast, $A$. niger-derived $\beta$-glycosidase is inhibited significantly by glucose, with $\sim 38 \%$ reduction in activity at glucose concentrations considered "dry" in winemaking (Günata et al. 1993).

In summary, endogenous glycosidases have poor stability in juice and wine due to the low $\mathrm{pH}$, and their ability to liberate conjugated aroma compounds is significantly inhibited by ethanol concentrations found in wine. In contrast, exogenous glycosidase are more stable at juice $\mathrm{pH}$ and are barely inhibited by ethanol but are strongly inhibited by glucose. Consequently, a large proportion of glycosidically bound compounds initially present in the grape remain after winemaking. Thus, application of commercial enzyme preparations to dry wines or slow acid hydrolysis during wine maturation (Williams 1993) can have important consequences on the final aroma profile of the wine. Further information about the activity of glucosidases can be found in a review (Maicas and Mateo 2005).

\section{Environmental Influences on Grape Aroma Compound Formation}

A recent study has indicated that $\sim 18 \%$ of genes in grapevine can be impacted by environmental conditions and that climate has the greatest effect on gene expression at veraison (Dal Santo et al. 2013). In particular, phenylpropanoid-related genes involved in the formation of aroma compounds and polyphenols were strongly impacted by seasonally specific climate conditions. The study provides a basic framework for future work aimed at integrating genomic information with studies of environmental and viticultural effects on grape and wine composition and flavor (Heymann and Cantu 2013).

Understanding these interrelationships may become even more important as the impacts of climate change on grapevine metabolism, water quality and availability, grape berry maturation, and other parameters become more apparent (Schultz 2000, Mira de Orduña 2010). In an interesting recent study, grape sensory properties (e.g., fruity and herbaceous aromas and juiciness) were influenced by elevated temperatures during the growing season even when all grapes were harvested at the same maturity as measured by Brix (Sadras et al. 2013). This study is unique in the use of a heating system to manipulate temperatures in the field, mimicking actual climate changes as closely as possible. Clearly, future well-controlled studies aimed at understanding the impact of climate changes on grape and wine composition and quality will be critical to ensure sustainable worldwide production of grapes and wines with desirable flavor attributes. 
Studies on the role of climate on grape composition may be difficult to interpret because climate encompasses all the environmental conditions of sunlight, temperature, humidity, and rainfall within a region, all of which play important roles in the growth and development of the vine and berry. In addition, the levels of aroma and aroma precursor compounds vary both between and within climates (Marais et al. 1991, Schneider et al. 2002). For example, levels of lutein, $\beta$-carotene (Marais et al. 1991), and 1,1,6-trimethyl-1,2-dihydronaphthalene (TDN) (Marais et al. 1992) have been found at higher concentrations in wines from warmer climates (South Africa) compared to cooler climates (Germany). On the other hand, the reverse relationship is observed with higher levels of methoxypyrazines in Sauvignon blanc from cool climates (New Zealand) compared to warm climates (Australia) (Lacey et al. 1991).

Whether these effects are due to temperature, sunlight exposure, or other variables associated with the different climates is unclear and this lack of clarity points to the difficulties in distinguishing effects of these interrelated variables. In the remainder of this section, we briefly review selected studies on the influence of vintage, sunlight, water and canopy management, grape maturity, and disease pressures on grape and wine aroma composition.

Vintage. The unique conditions of climate vary from year to year and it is commonly accepted worldwide that vintage has a major influence on fruit composition. Studies of aroma composition of Chardonnay (Sefton et al. 1993), Sauvignon blanc (Sefton et al. 1994), Semillon (Sefton et al. 1996), Merlot noir (Kotseridis et al. 1998), and Melon B (Schneider et al. 2001) have confirmed this observation on an analytical level. Global climate change may exacerbate the year-to-year variations, making understanding of this issue of great relevance to viticulturists (Schultz 2000).

Sunlight. The levels of numerous grape aroma compounds are influenced by light exposure. For example, exposure of fruit to sunlight favors accumulation of free norisoprenoids as well as glycosylated norisoprenoids, monoterpenes, and other non-terpene aglycones (Reynolds and Wardle 1989, Gerdes et al. 2002, Schneider et al. 2002, Lee et al. 2007, Skinkis et al. 2010). This increased accumulation of glycosides in grapes may be a factor of temperature as well as light exposure on enzyme activity within the fruit (Gerdes et al. 2002). On the other hand, light exposure has been observed to reduce the concentration of methoxypyrazines, although the timing of light exposure (pre- or postveraison) influences methoxypyrazine levels at harvest (Hashizume and Samuta 1999, Koch et al. 2012). Early season leaf removal also reduced methoxypyrazine levels in Cabernet franc and Merlot grapes; whether the findings were due to alterations in light exposure at the cluster is not known, since light measurements were not reported (Scheiner et al. 2010).

It has been suggested that quality and not intensity of light regulates the accumulation of norisoprenoid compounds $(\mathrm{Bu}-$ reau et al. 1998, Schultz 2000). These studies indicate that exposure to blue-green light (and potentially far-red wavelengths) results in synthesis of carotenoids (Bureau et al. 1998) as a photoprotective defense in vines (Young 1991,
Baumes et al. 2002). In addition, degradation of these carotenoids is enhanced by exposure to these same wavelengths of light (Bureau et al. 1998). The subsequent loss of carotenoids in grapes is observed once chloroplasts are lost or modified and carotenoid synthesis ceases (Baumes et al. 2002).

Water and canopy management. Vineyard practices, including canopy management and imposed water stress, are recommended ways of manipulating fruit light interception to attain the desired varietal aroma composition. In general, reduced vine water status is thought to alter carotenoid composition and norisoprenoid composition (Oliveira et al. 2003). In grapes, water deficits increased levels of carotenoids and selected $\mathrm{C}_{13}$-norisoprenoids produced from carotenoid degradation in some studies (Bindon et al. 2007, Grimplet et al. 2007), although the effect may depend on the norisoprenoid measured (Ou et al. 2010). These results are consistent with a recent study that indicates that regulation of carotenoid metabolism/degradation is highly complex and may occur at multiple levels (Young et al. 2012). Water deficits have had variable effects on monoterpene levels, with either no effect or elevating the concentrations of some compounds (Grimplet et al. 2007, Ou et al. 2010). Water deficits were not well correlated with levels of 3-isobutyl-2-methoxypyrazine in Cabernet Sauvignon wines (Chapman et al. 2005). Because water deficits accelerate the onset of ripening in field-grown vines, there appears to be an interrelationship between maturation and effects of water stress that may complicate the interpretation of these studies if not controlled or accounted for (Castellarin et al. 2007). In addition, water status can also influence canopy density (Hardie and Martin 2000) and consequently fruit light exposure as discussed previously.

Crop thinning (a common practice in vineyards) has been observed to increase levels of glycosylated terpenes and aliphatics, but no effect has been observed on the concentration of glycosylated norisoprenoids (Bureau et al. 2000). That may be explained by the independent biosynthesis of norisoprenoids in berries rather than their translocation from leaves (Günata et al. 2002). On the other hand, when crop yields were manipulated by winter pruning, a negative correlation was observed between crop yield and methoxypyrazine levels (Chapman et al. 2004).

Grape maturity. The ripening of grapes involves many processes, including translocation, accumulation, and metabolism of principal components within the berry. These changes include: (1) the uptake of sucrose from leaves via the phloem followed by its cleavage and storage as $\mathrm{D}(+)$-glucose and $\mathrm{D}(-)-$ fructose (Coombe 1992, Davies and Robinson 1996); (2) phloem dilution of $\mathrm{L}-(+)$-tartaric acid, synthesized from ascorbic acid preveraison (DeBolt et al. 2006), and metabolism of L-(-)malic acid (Ruffner 1982a, 1982b, Sweetman et al. 2009); (3) accumulation of amino acids, particularly arginine and proline, coupled to a decline in ammonium (Kliewer 1968, Stines et al. 2000, Bell and Henschke 2005); (4) decreased synthesis of phenols and accumulation of condensed tannins in the skin and seeds (Downey et al. 2003a, 2006); (5) accumulation of flavanols, anthocyanins (in red cultivars), and leuco-anthocyanins (in white cultivars) in the skins (Boss et al. 1996, 
Dokoozlian and Kliewer 1996, Downey et al. 2003b); and (6) changes in concentration and diversity of aroma precursors and volatile compounds (Reynolds and Wardle 1989, Lacey et al. 1991, Razungles et al. 1993, Dunlevy et al. 2009). These components collectively characterize the abundant organic compounds found in grapes that are used in wine production. In many cases, these components are subject to further biological and chemical modifications through the course of vinification and maturation. However, they essentially establish the basis of wine composition.

Several studies have monitored effects of maturation on levels of flavor compounds and their precursors, including carotenoids and norisoprenoid, monoterpenes, and methoxypyrazines. These studies indicate that carotenoids that accumulate before veraison degrade rapidly postveraison (Razungles et al. 1988, 1993, Marais et al. 1991). This rapid degradation occurs for $\beta$-carotene, lutein, and violaxanthin while neoxanthin levels decrease steadily (Razungles et al. 1996). The subsequent accumulation of norisoprenoids is inversely proportional to the degradation of these carotenoids and positively correlated with sugar accumulation (Strauss et al. 1987, Razungles et al. 1993). This relationship also exists for monoterpenes and is consistent with up-regulation of numerous genes involved in the early stages of terpene synthesis during maturation (Wilson et al. 1984, Martin et al. 2012). Studies of Sauvignon blanc, Cabernet Sauvignon, Cabernet franc, Carmenere, and Merlot have noted a decrease in methoxypyrazines with maturity (Allen et al. 1990, Lacey et al. 1991, Sala et al. 2000, Belancic and Agosin 2007).

It has been suggested that although changes in concentration of aroma compounds and sugar accumulation occur simultaneously, they may not be mutually dependent (Reynolds and Wardle 1989). Finally, while grape maturation is genetically controlled, it is also significantly influenced by environmental conditions, as noted above. Therefore, it can often be difficult to distinguish environmental influences on aroma composition from effects on grape maturation.

Fungal infections. Climate (e.g., temperature and humidity) as well as genetic variables (e.g., tightness of the berries in the cluster) can influence the susceptibility of grape clusters to fungal infections. As regional temperatures are altered as a result of global climate change, the susceptibility of grapes to fungal growth (e.g., Botrytis cinerea and Aspergillus niger) may also be affected with corresponding effects on grape flavor. For example, the common fungus $B$. cinerea causes gray bunch rot of grapes and has been observed to transform monoterpenes (Bock et al. 1988) and norisoprenoids (Schoch et al. 1991) in grape juice. Novel polyfunctional thiol cysteine conjugates were identified in botrytis-infected Sauvignon blanc and Semillon grapes that may contribute to the unique flavor of botrytized sweet wines (Thibon et al. 2010). Additionally, glycosidases derived from A. niger, although used commonly in analysis of grape glycosides (Winterhalter and Skouroumounis 1997), are known to generate oxidative artifacts of aromas when present at high concentrations (Sefton and Williams 1991). Although A. niger glycosidase is inactive at high concentrations of glucose (Günata et al. 1993), it does suggest that the associated infection of $A$. niger with $B$. cinerea (Nair 1985) could have compounding effects on the varietal aroma composition of infected grapes.

In summary, these studies point to the complexities involved in understanding the interrelationships among viticultural practices and fruit and wine composition and quality. Because multiple compounds are involved in flavor, practices that up-regulate selected metabolic pathways may also alter other pathways and metabolic products, making it difficult to predict the final outcome with respect to fruit composition. In most cases, mechanisms for the effects at the molecular level are also unknown, further complicating efforts to model and extrapolate results from one study to those of another in a different climate or region. Rather than examining effects on only one compound at a time, analytical profiling methods that measure concentrations of multiple compounds, combined with multivariate statistical analyses to relate genomic and sensory information, may provide valuable tools for future studies in this area and will be discussed in Part 2 .

\section{Summary}

It is apparent that the aroma of wine is dependent not on a particular compound but on the profile and interactions of the multiple odor-active compounds that are present. The potential aroma of wine is also dependent on the release of aroma compounds from their odorless precursors during wine maturation and the modification of volatiles due to chemical changes. Despite the great volume of research on wine composition, summarized in this review, there is still much to be learned about the biochemical and chemical origins of wine volatiles and the effects of climate and viticultural practices on the concentrations of these compounds. Understanding the source of wine volatile compounds and the mechanisms that influence their formation through grapegrowing, winemaking, and storage is essential to developing strategies for production of wines with specific sensory attributes that appeal to target markets.

\section{Literature Cited}

Acree, T.E., E.P. Sonoff, and D.F. Splittstoesser. 1972. Effect of yeast strain and type of sulfur compound on hydrogen sulfide production. Am. J. Enol. Vitic. 23:6-9.

Allen, M.S., M.J. Lacey, and S. Boyd. 1994. Determination of methoxypyrazines in red wines by stable isotope dilution gas chromatography-mass spectrometry. J. Agric. Food Chem. 42:1734-1738.

Allen, M.S., M.J. Lacey, W.V. Brown, and R.L.N. Harris. 1990. Occurrence of methoxypyrazines in grapes of Vitis vinifera cv. Cabernet Sauvignon and Sauvignon blanc. In Actualités Oenologiques 89: Comptes rendus du $4^{\mathrm{e}}$ Symposium International d'Oenologie, Bordeaux, 1989. P. Ribéreau-Gayon and A. Lonvaud (eds.), pp. 25-30. Institut d'Enologie Université de Bordeaux II/Dunod, Paris.

Allen, M.S., M.J. Lacey, R.L.N. Harris, and W.V. Brown. 1991. Contribution of methoxypyrazines to Sauvignon blanc wine aroma. Am. J. Enol. Vitic. 42:109-112.

Anness, B.J., and C.W. Bamforth. 1982. Dimethyl sulphide-A review. J. Inst. Brew. 88:244-252.

Aryan, A.P., B. Wilson, C.R. Strauss, and P.J. Williams. 1987. The properties of glycosidases of Vitis vinifera and a comparison of their $\beta$-glucosidase activity with that of exogenous enzymes. An assessment of possible applications in enology. Am. J. Enol. Vitic. 38:182-188. 
Atanasova, B., T. Thomas-Danguin, D. Langlois, S. Nicklaus, C. Chabanet, and P. Etiévant. 2005. Perception of wine fruity and woody notes: Influence of peri-threshold odorants. Food Qual. Pref. 16:504-510.

Auldridge, M.E., A. Block, J.T. Vogel, C. Dabney-Smith, I. Mila, M. Bouzayen, M. Magallanes-Lundback, D. DellaPenna, D.R. McCarty, and H.J. Klee. 2006. Characterization of three members of the Arabidopsis carotenoid cleavage dioxygenase family demonstrates the divergent roles of this multifunctional enzyme family. Plant $J$. 45:982-993.

Auvray, M., and C. Spence. 2008. The multisensory perception of flavor. Conscious Cogn. 17:1016-1031.

Bailly, S., V. Jerkovic, J. Marchand-Brynaert, and S. Collin. 2006. Aroma extraction dilution analysis of Sauternes wines. Key role of polyfunctional thiols. J. Agric. Food Chem. 54:7227-7234.

Bailly, S., V. Jerkovic, A. Meurée, A. Timmermans, and S. Collin. 2009. Fate of key odorants in Sauternes wines through aging. J. Agric. Food Chem. 57:8557-8563.

Bardi, L., C. Cocito, and M. Marzona. 1999. Saccharomyces cerevisiae cell fatty acid composition and release during fermentation without aeration and in absence of exogenous lipids. Int. J. Food Microbiol. 47:133-140.

Bartowsky, E.J., and I.S. Pretorius. 2009. Microbial formation and modification of flavor and off-flavor compounds in wine. In Biology of Microorganisms on Grapes, in Must and in Wine. H. König et al. (eds.), pp. 209-231. Springer-Verlag, Berlin.

Battilana, J., L. Costantini, F. Emanuelli, F. Sevini, C. Segala, S. Moser, R. Velasco, G. Versini, and M.S. Grando. 2009. The 1-deoxyD-xylulose 5-phosphate synthase gene co-localizes with a major QTL affecting monoterpene content in grapevine. Theor. Appl. Genet. 118:653-669.

Battilana J., F. Emanuelli, G. Gambino, I. Gribaudo, F. Gasperi, P.K. Boss, and M.S. Grando. 2011. Functional effect of grapevine 1-deoxy-D-xylulose 5-phosphate synthase substitution K284N on Muscat flavour formation. J. Exp. Bot. 62:5497-5508.

Baumes, R., J. Wirth, S. Bureau, Y. Gunata, and A. Razungles. 2002. Biogeneration of $\mathrm{C}_{13}$-norisoprenoid compounds: Experiments supportive for an apo-carotenoid pathway in grapevines. Anal. Chim. Acta 458:3-14.

Baxter, R.L., W.A. Laurie, and D. McHale. 1978. Transformations of monoterpenoids in aqueous acids: The reactions of linalool, geraniol, nerol and their acetates in aqueous citric acid. Tetrahedron 34:2195-2199.

Belancic, A., and E. Agosin. 2007. Methoxypyrazines in grapes and wines of Vitis vinifera cv. Carmenere. Am. J. Enol. Vitic. 58:462-469.

Bell, S.J., and P.A. Henschke. 2005. Implications of nitrogen nutrition for grapes, fermentation and wine. Aust. J. Grape Wine Res. 11:242-295.

Benkwitz, F., T. Tominaga, P.A. Kilmartin, C. Lund, M. Wohlers, and L. Nicolau. 2012. Identifying the chemical composition related to the distinct aroma characteristics of New Zealand Sauvignon blanc wines. Am. J. Enol. Vitic. 63:62-72.

Bindon, K.A., P.R. Dry, and B.R. Loveys. 2007. Influence of plant water status on the production of $\mathrm{C}_{13}$-norisoprenoid precursors in Vitis vinifera L. cv. Cabernet Sauvignon grape berries. J. Agric. Food Chem. 55:4493-4500.

Bindon, K.A., P.A. Smith, and J.A. Kennedy. 2010. Interaction between grape-derived proanthocyanidins and cell wall material. 1. Effect on proanthocyanidin composition and molecular mass. J. Agric. Food Chem. 58:2520-2528.

Bisson, L.F. 1999. Stuck and sluggish fermentations. Am. J. Enol. Vitic. 50:107-119.
Bisson, L.F., and J.E. Karpel. 2010. Genetics of yeast impacting wine quality. Ann. Rev. Food Sci. Technol. 1:139-162.

Bock, G., I. Benda, and P. Schreier. 1988. Microbial transformation of geraniol and nerol by Botrytis cinerea. Appl. Microbiol. Biotechnol. 27:351-357.

Boido, E., A. Lloret, K. Medina, L. Farñia, F. Carrau, G. Versini, and E. Dellacassa. 2003. Aroma composition of Vitis vinifera cv. Tannat: The typical red wine from Uruguay. J. Agric. Food Chem. 51:5408-5413.

Boido, E., K. Medina, L. Fariña, F. Carrau, G. Versini, and E. Dellacassa. 2009. The effect of bacterial strain and aging on the secondary volatile metabolites produced during malolactic fermentation of Tannat red wine. J. Agric. Food Chem. 57:6271-6278.

Boss, P.K., C. Davies, and S.P. Robinson. 1996. Analysis of the expression of anthocyanin pathway genes in developing Vitis vinifera $\mathrm{L}$. cv Shiraz grape berries and the implications for pathway regulation. Plant Physiol. 111:1059-1066.

Britton, G. 1995. Structure and properties of carotenoids in relation to function. FASEB J. 9:1551-1558.

Buck, L., and R. Axel. 1991. A novel multigene family may encode odorant receptors: A molecular basis for odor recognition. Cell $65: 175-187$

Bureau, S.M., R.L. Baumes, and A.J. Razungles. 2000. Effects of vine or bunch shading on the glycosylated flavor precursors in grapes of Vitis vinifera L. cv. Syrah. J. Agric. Food Chem. 48:1290-1297.

Bureau, S.M., A.J. Razungles, R.L. Baumes, and C.L. Bayonove. 1998. Effect of qualitative modification of light on the carotenoid contents in Vitis vinifera L. cv. Syrah berries. Sci. Aliments 18:485-495.

Buttery, R.G., R.M. Seifert, D.G. Guadagni, and L. Ling. 1969. Characterization of some volatile constituents of bell peppers. J. Agric. Food Chem. 17:1322-1327.

Cadahía, E., B. Fernández de Simón, and J. Jalocha. 2003. Volatile compounds in Spanish, French, and American oak woods after natural seasoning and toasting. J. Agric. Food Chem. 51:5923-5932.

Callejon, R.M., A. Clavijo, P. Ortigueira, A.M. Troncoso, P. Paneque, and M.L. Morales. 2010. Volatile and sensory profile of organic red wines produced by different selected autochthonous and commercial Saccharomyces cerevisiae strains. Anal. Chim. Acta 660:68-75.

Campo, E., V. Ferreira, A. Escudero, and J. Cacho. 2005. Prediction of the wine sensory properties related to grape variety from dynamicheadspace gas chromatography-olfactometry data. J. Agric. Food Chem. 53:5682-5690.

Canuti, V., M. Conversano, M. Li Calzi, H. Heymann, M.A. Matthews, and S.E. Ebeler. 2009. Headspace solid-phase microextraction-gas chromatography-mass spectrometry for profiling free volatile compounds in Cabernet Sauvignon grapes and wines. J. Chromatogr., A 1216:3012-3022.

Capone, D.L., and D.W. Jeffery. 2011. Effects of transporting and processing Sauvignon blanc grapes on 3-mercaptohexan-1-ol precursor concentrations. J. Agric. Food Chem. 59:4659-4667.

Capone, D.L., D.W. Jeffery, and M.A. Sefton. 2012. Vineyard and fermentation studies to elucidate the origin of 1,8-cineole in Australian red wine. J. Agric. Food Chem. 60:2281-2287.

Capone, D.L., K.H. Pardon, A.G. Cordente, and D.W. Jeffery. 2011. Identification and quantitation of 3-S-cysteinylglycinehexan-1-ol (cysgly-3-MH) in Sauvignon blanc grape juice by HPLC-MS/MS. J. Agric. Food Chem. 59:11204-11210.

Capone, D.L., M.A. Sefton, Y. Hayasaka, and D.W. Jeffery. 2010. Analysis of precursors to wine odorant 3-mercaptohexan-1-ol using HPLC-MS/MS: Resolution and quantitation of diastereomers of 3-S-cysteinylhexan-1-ol and 3-S-glutathionylhexan-1-ol. J. Agric. Food Chem. 58:1390-1395. 
Caputi, L., E.K. Lim, and D.J. Bowles. 2008. Discovery of new biocatalysts for the glycosylation of terpenoid scaffolds. Chem. Eur. J. 14:6656-6662.

Castellarin, S., M.A. Matthews, G.D. Gaspero, and G.A. Gambetta. 2007. Water deficits accelerate ripening and induce changes in gene expression regulating flavonoid biosynthesis in grape berries. Planta 227:101-112.

Chapman, D.M., G. Roby, S.E. Ebeler, J.X. Guinard, and M.A. Matthews. 2005. Sensory attributes of Cabernet Sauvignon wines made from vines with different water status. Aust. J. Grape Wine Res. 11:339-347.

Chapman, D.M., J.H. Thorngate, M.A. Matthews, J.X. Guinard, and S.E. Ebeler. 2004. Yield effects on 2-methoxy-3-isobutylpyrazine concentration in Cabernet Sauvignon using a solid phase microextraction gas chromatography/mass spectrometry method. J. Agric. Food Chem. 52:5431-5435.

Chassagne, D., J. Crouzet, C.L. Bayonove, and R.L. Baumes. 1998. Identification of passion fruit glycosides by gas chromatography/ mass spectrometry. J. Agric. Food Chem. 46:4352-4357.

Chatonnet, P., I. Cutzach, M. Pons, and D. Dubourdieu. 1999. Monitoring toasting intensity of barrels by chromatographic analysis of volatile compounds from toasted oak wood. J. Agric. Food Chem. 47:4310-4318.

Chatonnet, P., D. Dubourdieu, and J.N. Boidron. 1995. The influence of Brettanomyces/Dekkera sp. yeasts and lactic acid bacteria on the ethylphenol content of red wines. Am. J. Enol. Vitic. 46:463-468.

Chatonnet, P., D. Dubourdieu, J.N. Boidron, and V. Lavigne. 1993. Synthesis of volatile phenols by Saccharomyces cerevisiae in wines. J. Sci. Food Agric. 62:191-202.

Chatonnet, P., D. Dubourdieu, J.N. Boidron, and M. Pons. 1992. The origin of ethylphenols in wines. J. Sci. Food Agric. 60:165-178.

Coelho, E., S.M. Rocha, I. Delgadillo, and M.A. Coimbra. 2006. Headspace-SPME applied to varietal volatile components evolution during Vitis vinifera L. cv. 'Baga' ripening. Anal. Chim. Acta 563:204-214

Coetzee, C., and W.J. du Toit. 2012. A comprehensive review on Sauvignon blanc aroma with a focus on certain positive volatile thiols. Food Res. Int. 45:287-298.

Cohen, S.D., and J.A. Kennedy. 2010. Plant metabolism and the environment: Implications for managing phenolics. Crit. Rev. Food Sci. Nutr. 50:620-643.

Cooke, R.C., K.A. van Leeuwen, D.L. Capone, R. Gawel, G.M. Elsey, and M.A. Sefton. 2009. Odor detection thresholds and enantiomeric distributions of several 4-alkyl substituted $\gamma$-lactones in Australian red wine. J. Agric. Food Chem. 57:2462-2467.

Coombe, B.G. 1992. Research on development and ripening of the grape berry. Am. J. Enol. Vitic. 43:101-110.

Cordente, A.G., C.D. Curtin, C. Varela, and I.S. Pretorius. 2012. Flavour-active wine yeasts. Appl. Microbiol. Biotechnol. 96:601-618.

Couto, J.A., F.M. Campos, A.R. Figueiredo, and T.A. Hogg. 2006. Ability of lactic acid bacteria to produce volatile phenols. Am. J. Enol. Vitic. 57:166-171.

Cox, A., D.L. Capone, G.M. Elsey, M.V. Perkins, and M.A. Sefton. 2005. Quantitative analysis, occurrence, and stability of $(E)$ 1-(2,3,6-trimethylphenyl)buta-1,3-diene in wine. J. Agric. Food Chem. 53:3584-3591.

Crowell, E.A., J.F. Guymon, and J.L. Ingraham. 1961. Techniques for studying the mechanism of higher alcohol formation by yeasts. Am. J. Enol. Vitic. 12:111-116.

Cutzach, I., P. Chatonnet, R. Henry, and D. Dubourdieu. 1997. Identification of volatile compounds with a "toasty" aroma in heated oak used in barrelmaking. J. Agric. Food Chem. 45:2217-2224.
Cutzach, I., P. Chatonnet, R. Henry, and D. Dubourdieu. 1999. Identifying new volatile compounds in toasted oak. J. Agric. Food Chem. 47:1663-1667.

Dal Santo, S., G. B. Tornielli, S. Zenoni, M. Fasoli, L. Farina, A. Anesi, F. Guzzo, M. Delledonne, and M. Pezzotti. 2013. The plasticity of the grapevine berry transcriptome. Genome Biol. 14:R54.

Darriet, P., T. Tominaga, V. Lavigne, J.N. Boidron, and D. Dubourdieu. 1995. Identification of a powerful aromatic component of Vitis vinifera $\mathrm{L}$. var. Sauvignon wines: 4-Mercapto-4-methylpentan-2-one. Flavour Frag. J. 10:385-392.

Davies, C., and S.P. Robinson. 1996. Sugar accumulation in grape berries: Cloning of two putative vacuolar invertase cDNAs and their expression in grapevine tissues. Plant Physiol. 111:275-283.

De La Presa-Owens, C., and A.C. Noble. 1997. Effect of storage at elevated temperatures on aroma of Chardonnay wines. Am. J. Enol. Vitic. 48:310-316.

De Mora, S.J., R. Eschenbruch, S.J. Knowles, and D.J. Spedding. 1986. The formation of dimethyl sulphide during fermentation using a wine yeast. Food Microbiol. 3:27-32.

de Revel, G., N. Martin, L. Pripis-Nicolau, A. Lonvaud-Funel, and A. Bertrand. 1999. Contribution to the knowledge of malolactic fermentation influence on wine aroma. J. Agric. Food Chem. 47:4003-4008.

DeBolt, S., D.R. Cook, and C.M. Ford. 2006. L-Tartaric acid synthesis from vitamin $\mathrm{C}$ in higher plants. Proc. Nat. Acad. Sci. USA 103:5608-5613.

Delcroix, A., Z. Günata, J.C. Sapis, J.M. Salmon, and C. Bayonove. 1994. Glycosidase activities of three enological yeast strains during winemaking: Effect on the terpenol content of Muscat wine. Am. J. Enol. Vitic. 45:291-296.

Demmig-Adams, B. 1990. Carotenoids and photoprotection in plants: A role for the xanthophyll zeaxanthin. Biochim. Biophys. Acta 1020:1-24.

Demmig-Adams, B., and W.W. Adams. 1996. The role of xanthophyll cycle carotenoids in the protection of photosynthesis. Trends Plant Sci. 1:21-26.

Demole, E., P. Enggist, U. Säuberli, M. Stoll, and E. Sz. Kováts. 1970. Structure et synthèse de la damascénone (triméthyl-2,6,6-transcrotonoyl-1-cyclohexadiène-1,3), constituant odorant de l'essence de rose bulgare (Rosa damascena Mill.). Helv. Chim. Acta 53:541-551.

Dennis, E.G., R.A. Keyzers, C.M. Kalua, S.M. Maffei, E.L. Nicholson, and P.K. Boss. 2012. Grape contribution to wine aroma: Production of hexyl acetate, octyl acetate, and benzyl acetate during yeast fermentation is dependent upon precursors in the must. J. Agric. Food Chem. 60:2638-2646.

Dimitriadis, E., and P.J. Williams. 1984. The development and use of a rapid analytical technique for estimation of free and potentially volatile monoterpene flavorants of grapes. Am. J. Enol. Vitic. 35:66-71.

Dokoozlian, N.K., and W.M. Kliewer. 1996. Influence of light on grape berry growth and composition varies during fruit development. J. Am. Soc. Hortic. Sci. 121:869-874.

Downey, M.O., N.K. Dokoozlian, and M.P. Krstic. 2006. Cultural practice and environmental impacts on the flavonoid composition of grapes and wine: A review of recent research. Am. J. Enol. Vitic. 57:257-268.

Downey, M.O., J.S. Harvey, and S.P. Robinson. 2003a. Analysis of tannins in seeds and skins of Shiraz grapes throughout berry development. Aust. J. Grape Wine Res. 9:15-27.

Downey, M.O., J.S. Harvey, and S.P. Robinson. 2003b. Synthesis of flavonols and expression of flavonol synthase genes in the developing grape berries of Shiraz and Chardonnay (Vitis vinifera L.). Aust. J. Grape Wine Res. 9:110-121.

Du, X.F., A. Kurnianta, M. McDaniel, C.E. Finn, and M.C. Qian. 2010. Flavour profiling of 'Marion' and thornless blackberries by instrumental and sensory analysis. Food Chem. 121:1080-1088. 
Dubourdieu, D., and T. Tominaga. 2009. Polyfunctional thiol compounds. In Wine Chemistry and Biochemistry. M.V. Moreno-Arribas and M.C. Polo (eds.), pp. 275-293. Springer, New York.

Dubourdieu, D., T. Tominaga, I. Masneuf, C. Peyrot des Gachons, and M.L. Murat. 2006. The role of yeasts in grape flavor development during fermentation: The example of Sauvignon blanc. Am. J. Enol. Vitic. 57:81-88.

Dudareva, N., and E. Pichersky. 2006. Floral scent metabolic pathways: Their regulation and evolution. In Biology of Floral Scent. N. Dudareva and E. Pichersky (eds.), pp. 55-78. Taylor and Francis, Boca Raton, FL.

Dudareva, N., E. Pichersky, and J. Gershenzon. 2004. Biochemistry of plant volatiles. Plant Physiol. 135:1893-1902.

Dunlevy, J.D., E.G. Dennis, K.L. Soole, M.V. Perkins, C. Davies, and P.K. Boss. 2013. A methyltransferase essential for the methoxypyrazine-derived flavour of wine. Plant J. 75:606-617.

Dunlevy, J.D., C.M. Kalua, R.A. Keyzers, and P.K. Boss. 2009. The production of flavour and aroma compounds in grape berries. In Grapevine Molecular Physiology and Biotechnology. K.A. RoubelakisAngelakis (ed.), pp. 293-340. Springer, Dordrecht, Netherlands.

Dunlevy, J.D., K.L. Soole, M.V. Perkins, E.G. Dennis, R.A. Keyzers, C.M. Kalua, and P.K. Boss. 2010. Two $O$-methyltransferases involved in the biosynthesis of methoxypyrazines: Grape-derived aroma compounds important to wine flavour. Plant Mol. Biol. 74:77-89.

Ebeler, S.E. 2001. Analytical chemistry: Unlocking the secrets of wine flavor. Food Rev. Int. 17:45-64.

Ebeler, S.E., and J.H. Thorngate. 2009. Wine chemistry and flavor: Looking into the crystal glass. J. Agric. Food Chem. 57:8098-8108.

Edwards, C.G., R.B. Beelman, C.E. Bartley, and A.L. McConnell. 1990. Production of decanoic acid and other volatile compounds and the growth of yeast and malolactic bacteria during vinification. Am. J. Enol. Vitic. 41:48-56.

Emanuelli, F., J. Battilana, L. Costantini, L. Le Cunff, J.M. Boursiquot, P. This, and M.S. Grando. 2010. A candidate gene association study on Muscat flavor in grapevine (Vitis vinifera L.). BMC Plant Biol. 10:241

Escudero, A., E. Asensio, J. Cacho, and V. Ferreira. 2002. Sensory and chemical changes of young white wines stored under oxygen. An assessment of the role played by aldehydes and some other important odorants. Food Chem. 77:325-331.

Escudero, A., E. Campo, L. Fariña, J. Cacho, and V. Ferreira. 2007. Analytical characterization of the aroma of five premium red wines. Insights into the role of odor families and the concept of fruitiness of wines. J. Agric. Food Chem. 55:4501-4510.

Escudero, A., P. Hernández-Orte, J. Cacho, and V. Ferreira. 2000. Clues about the role of methional as character impact odorant of some oxidized wines. J. Agric. Food Chem. 48:4268-4272.

Falcão, L.D., G. De Revel, M.C. Perello, A. Moutsiou, M.C. Zanus, and M.T. Bordignon-Luiz. 2007. A survey of seasonal temperatures and vineyard altitude influences on 2-methoxy-3-isobutylpyrazine, $\mathrm{C}_{13}$-norisoprenoids, and the sensory profile of Brazilian Cabernet Sauvignon wines. J. Agric. Food Chem. 55:3605-3612.

Fan, J., C. Chen, Q. Yu, Z.G. Li, and F.G. Gmitter. 2010. Characterization of three terpenoid glycosyltransferase genes in 'Valencia' sweet orange (Citrus sinensis L. Osbeck). Genome 53:816-823.

Fedrizzi, B., F. Magno, D. Badocco, G. Nicolini, and G. Versini. 2007. Aging effects and grape variety dependence on the content of sulfur volatiles in wine. J. Agric. Food Chem. 55:10880-10887.

Fedrizzi, B., K.H. Pardon, M.A. Sefton, G.M. Elsey, and D.W. Jeffery. 2009. First identification of 4-S-glutathionyl-4-methylpentan-2-one, a potential precursor of 4-mercapto-4-methylpentan-2-one, in Sauvignon blanc juice. J. Agric. Food Chem. 57:991-995.
Fernández de Simón, B., E. Cadahía, M. del Álamo, and I. Nevares. 2010a. Effect of size, seasoning and toasting in the volatile compounds in toasted oak wood and in a red wine treated with them. Anal. Chim. Acta 660:211-220.

Fernández de Simón, B., E. Cadahía, I. Muiño, M. Del Álamo, and I. Nevares. 2010b. Volatile composition of toasted oak chips and staves and of red wine aged with them. Am. J. Enol. Vitic. 61:157-165.

Ferreira, B., C. Hory, M.H. Bard, C. Taisant, A. Olsson, and Y. Le Fur. 1995. Effects of skin contact and settling on the level of the C18:2, C18:3 fatty acids and C6 compounds in Burgundy Chardonnay musts and wines. Food Qual. Pref. 6:35-41.

Ferreira, V., R. López, and J.F. Cacho. 2000. Quantitative determination of the odorants of young red wines from different grape varieties. J. Sci. Food Agric. 80:1659-1667.

Ferreira, V., N. Ortín, A. Escudero, R. López, and J. Cacho. 2002. Chemical characterization of the aroma of Grenache rosé wines: Aroma extract dilution analysis, quantitative determination, and sensory reconstitution studies. J. Agric. Food Chem. 50:4048-4054.

Firestein, S. 2001. How the olfactory system makes sense of scents. Nature 413:211-218.

Floss, D. S., W. Schliemann, J. Schmidt, D. Strack, and M. H. Walter. 2008. RNA interference-mediated repression of MtCCD1 in mycorrhizal roots of Medicago truncatula causes accumulation of $\mathrm{C}_{27}$ apocarotenoids, shedding light on the functional role of CCD1. Plant Physiol. 148:1267-1282.

Francis, I.L., and J.L. Newton. 2005. Determining wine aroma from compositional data. Aust. J. Grape Wine Res. 11:114-126.

Francis, I.L., S. Kassara, A.C. Noble, and P.J. Williams. 1998. The contribution of glycoside precursors to Cabernet Sauvignon and Merlot aroma: Sensory and compositional studies. In Chemistry of Wine Flavor. A.L. Waterhouse and S.E. Ebeler (eds.), pp. 13-30. ACS Symp. Series 714. Am. Chemical Society, Washington, DC.

Francis, I.L., M.A. Sefton, and P.J. Williams. 1992. A study by sensory descriptive analysis of the effects of oak origin, seasoning, and heating on the aromas of oak model wine extracts. Am. J. Enol. Vitic. 43:23-30.

Full, G., and P. Winterhalter. 1994. Application of on-line coupled mass-spectrometric techniques for the study of isomeric vitispiranes and their precursors of grapevine cv. Riesling. Vitis 33:241-244.

Gaillard, I., S. Rouquier, and D. Giorgi. 2004. Olfactory receptors. Cell. Mol. Life Sci. 61:456-469.

Galvan, T.L., S. Kells, and W.D. Hutchison. 2008. Determination of 3-alkyl-2-methoxypyrazines in lady beetle-infested wine by solidphase microextraction headspace sampling. J. Agric. Food Chem. 56:1065-1071.

Garde-Cerdan, T., and C. Ancin-Azpilicueta. 2006. Review of quality factors on wine ageing in oak barrels. Tr. Food Sci. Technol. 17:438-447.

Garde-Cerdan, T., C. Lorenzo, J.M. Carot, M. D. Esteve, M.D. Climent, and M.R. Salinas. 2010. Effects of composition, storage time, geographic origin and oak type on the accumulation of some volatile oak compounds and ethylphenols in wines. Food Chem. 122:1076-1082.

Gawel, R. 1998. Red wine astringency: A review. Aust. J. Grape Wine Res. 4:74-95.

Genovese, A., A. Gambuti, P. Piombino, and L. Moio. 2007. Sensory properties and aroma compounds of sweet Fiano wine. Food Chem. 103:1228-1236.

Genovese, A., P. Piombino, M.T. Lisanti, and L. Moio. 2005. Determination of furaneol (4-hydroxy-2,5-dimethyl-3(2H)-furanone) in some wines from Italian native grapes by gas-chromatography-sim/ mass spectrometry. Ann. Chim. 95:415-419.

Gerdes, S.M., P. Winterhalter, and S.E. Ebeler. 2002. Effect of sunlight exposure on norisoprenoid formation in White Riesling grapes. In Carotenoid-Derived Aroma Compounds. P. Winterhalter and R. 
Rouseff (eds.), pp. 262-272. ACS Symp. Series 802. Am. Chemical Society, Washington, DC.

Ghidossi, R., C. Poupot, C. Thibon, A. Pons, P. Darriet, L. Riquier, G. De Revel, and M. Mietton Peuchot. 2012. The influence of packaging on wine conservation. Food Control 23:302-311.

Gholami, M., Y. Hayasaka, B.G. Coombe, J.F. Jackson, S.P. Robinson, and P.J. Williams. 1995. Biosynthesis of flavour compounds in Muscat Gordo Blanco grape berries. Aust. J. Grape Wine Res. 1:19-24.

Giudici, P., and R.E. Kunkee. 1994. The effect of nitrogen deficiency and sulfur-containing amino acids on the reduction of sulfate to hydrogen sulfide by wine yeasts. Am. J. Enol. Vitic. 45:107-112.

Gómez-Plaza, E., L.J. Pérez-Prieto, J.I. Fernández-Fernández, and J.M. López-Roca. 2004. The effect of successive uses of oak barrels on the extraction of oak-related volatile compounds from wine. Int. J. Food Sci. Technol. 39:1069-1078.

Goniak, O.J., and A.C. Noble. 1987. Sensory study of selected volatile sulfur compounds in white wine. Am. J. Enol. Vitic. 38:223-227.

González-Barreiro, C., R. Rial-Otero, B. Cancho-Grande, and J. Simal-Gándara. 2013. Wine aroma compounds in grapes: A critical review. Crit. Rev. Food Sci. Nutr. doi: 10.1080/10408398.2011.650336.

Grant-Preece, P.A., K.H. Pardon, D.L. Capone, A.G. Cordente, M.A. Sefton, D.W. Jeffery, and G.M. Elsey. 2010. Synthesis of wine thiol conjugates and labeled analogues: Fermentation of the glutathione conjugate of 3-mercaptohexan-1-ol yields the corresponding cysteine conjugate and free thiol. J. Agric. Food Chem. 58:1383-1389.

Grimaldi, A., E. Bartowsky, and V. Jiranek. 2005a. Screening of Lactobacillus spp. and Pediococcus spp. for glycosidase activities that are important in oenology. J. Appl. Microbiol. 99:1061-1069.

Grimaldi, A., E. Bartowsky, and V. Jiranek. 2005b. A survey of glycosidase activities of commercial wine strains of Oenococcus oeni. Int. J. Food Microbiol. 105:233-244.

Grimplet, J., L.G. Deluc, R.L. Tillett, M.D. Wheatley, K.A. Schlauch, G.R. Cramer, and J.C. Cushman. 2007. Tissue-specific mRNA expression profiling in grape berry tissues. BMC Genomics 8:187.

Guedes de Pinho, P., A.C.S. Ferreira, M.M. Pinto, J.G. Benitez, and T.A. Hogg. 2001. Determination of carotenoid profiles in grapes, musts, and fortified wines from Douro varieties of Vitis vinifera. J. Agric. Food Chem. 49:5484-5488.

Guedes de Pinho, P., and A. Bertrand. 1995. Analytical determination of furaneol (2,5-dimethyl-4-hydroxy-3(2H)-furanone). Application to differentiation of white wines from hybrid and various Vitis vinifera cultivars. Am. J. Enol. Vitic. 46:181-186.

Guillaumie, S., R. Fouquet, C. Kappel, C. Camps, N. Terrier, D. Moncomble, J. Dunlevy, C. Davies, P. Boss, and S. Delrot. 2011. Transcriptional analysis of late ripening stages of grapevine berry. BMC Plant Biol. 11:165.

Guillaumie, S., et al. 2013. Genetic analysis of the biosynthesis of 2-methoxy-3-isobutylpyrazine, a major grape-derived aroma compound impacting wine quality. Plant Physiol. 162:604-615.

Guillén, M.D., and M.J. Manzanos. 2002. Study of the volatile composition of an aqueous oak smoke preparation. Food Chem. 79:283-292.

Guitart, A., P. Hernández Orte, V. Ferreira, C. Peña, and J. Cacho. 1999. Some observations about the correlation between the amino acid content of musts and wines of the Chardonnay variety and their fermentation aromas. Am. J. Enol. Vitic. 50:253-258.

Günata, Y.Z., C.L. Bayonove, C. Tapiero, and R.E. Cordonnier. 1990. Hydrolysis of grape monoterpenyl $\beta$-D-glucosides by various $\beta$-glucosidases. J. Agric. Food Chem. 38:1232-1236.

Günata, Y.Z., C.L. Bayonove, R.L. Baumes, and R.E. Cordonnier. 1985. The aroma of grapes. I. Extraction and determination of free and glycosidically bound fractions of some grape aroma components. J. Chromatogr., A 331:83-90.
Günata, Y.Z., C.L. Bayonove, R.L. Baumes, and R.E. Cordonnier. 1986. Stability of free and bound fractions of some aroma components of grapes cv. Muscat during the wine processing: Preliminary results. Am. J. Enol. Vitic. 37:112-114.

Günata, Z., I. Dugelay, J.C. Sapis, R. Baumes, and C. Bayonove. 1993. Role of enzymes in the use of the flavour potential from grape glycosides in winemaking. In Progress in Flavour Precursor Studies: Analysis, Generation, Biotechnology. P. Schreier and P. Winterhalter (eds.), pp. 219-234. Allured Publishing, Carol Stream, IL.

Günata, Z., J.L. Wirth, W. Guo, and R.L. Baumes. 2002. $\mathrm{C}_{13}$-norisoprenoid aglycon composition of leaves and grape berries from Muscat of Alexandria and Shiraz cultivars. In Carotenoid-Derived Aroma Compounds. P. Winterhalter and R. Rouseff (eds.), pp. 255-261. ACS Symp. Series 802. Am. Chemical Society, Washington, DC.

Guth, H. 1997a. Identification of character impact odorants of different white wine varieties. J. Agric. Food Chem. 45:3022-3026.

Guth, H. 1997b. Quantitation and sensory studies of character impact odorants of different white wine varieties. J. Agric. Food Chem. 45:3027-3032.

Haleva-Toledo, E., M. Naim, U. Zehavi, and R.L. Rouseff. 1999. Formation of $\alpha$-terpineol in citrus juices, model and buffer solutions. J. Food Sci. 64:838-841.

Hansen, J., and P. Francke Johannesen. 2000. Cysteine is essential for transcriptional regulation of the sulfur assimilation genes in Saccharomyces cerevisiae. Mol. Genet. Genomics 263:535-542.

Harbertson, J.F., R.E. Hodgins, L.N. Thurston, L.J. Schaffer, M.S. Reid, J.L. Landon, C.F. Ross, and D.O. Adams. 2008. Variability of tannin concentration in red wines. Am. J. Enol. Vitic. 59:210-214.

Hardie, W.J., and S.R. Martin. 2000. Shoot growth on de-fruited grapevines: A physiological indicator for irrigation scheduling. Aust. J. Grape Wine Res. 6:52-58.

Hardie, W.J., S.J. Aggenbach, and V.G. Jaudzems. 1996. The plastids of the grape pericarp and their significance in isoprenoid synthesis. Aust. J. Grape Wine Res. 2:144-154.

Harris, V., C.M. Ford, V. Jiranek, and P.R. Grbin. 2008. Dekkera and Brettanomyces growth and utilisation of hydroxycinnamic acids in synthetic media. Appl. Microbiol. Biotechnol. 78:997-1006.

Hashizume, K., and T. Samuta. 1999. Grape maturity and light exposure affect berry methoxypyrazine concentration. Am. J. Enol. Vitic. 50:194-198.

Hashizume, K., K. Tozawa, M. Endo, and I. Aramaki. 2001. S-AdenosylL-methionine-dependent $O$-methylation of 2-hydroxy-3-alkylpyrazine in wine grapes: A putative final step of methoxypyrazine biosynthesis. Biosci. Biotech. Biochem. 65:795-801.

Hasin-Brumshtein, Y., D. Lancet, and T. Olender. 2009. Human olfaction: From genomic variation to phenotypic diversity. Trends Genet. 25:178-184.

Hayasaka, Y., G.A. Baldock, M. Parker, K.H. Pardon, C.A. Black, M.J. Herderich, and D.W. Jeffery. 2010. Glycosylation of smoke-derived volatile phenols in grapes as a consequence of grapevine exposure to bushfire smoke. J. Agric. Food Chem. 58:10989-10998.

Hernández-Orte, P., J.F. Cacho, and V. Ferreira. 2002. Relationship between varietal amino acid profile of grapes and wine aromatic composition. Experiments with model solutions and chemometric study. J. Agric. Food Chem. 50:2891-2899.

Hernández-Orte, P., M.J. Ibarz, J. Cacho, and V. Ferreira. 2005. Effect of the addition of ammonium and amino acids to musts of Airen variety on aromatic composition and sensory properties of the obtained wine. Food Chem. 89:163-174.

Herraiz, T., and C.S. Ough. 1993. Formation of ethyl esters of amino acids by yeasts during the alcoholic fermentation of grape juice. Am. J. Enol. Vitic. 44:41-48. 
Heymann, H., and D. Cantu. 2013. Systems biology of vintage and terroir: Adding some flavor to the wine grape transcriptome. Flavour 2:20.

Hocking, A.D., S.L.L. Leong, B.A. Kazi, R.W. Emmett, and E.S. Scott. 2007. Fungi and mycotoxins in vineyards and grape products. Int. J. Food Microbiol. 119:84-88.

Holt, S., A.G. Cordente, S.J. Williams, D.L. Capone, W. Jitjaroen, I.R. Menz, C. Curtin, and P.A. Anderson. 2011. Engineering Saccharomyces cerevisiae to release 3-mercaptohexan-1-ol during fermentation through overexpression of an S. cerevisiae gene, STR3, for improvement of wine aroma. Appl. Environ. Microbiol. 77:3626-3632.

Howell, K.S., M. Klein, J.H. Swiegers, Y. Hayasaka, G.M. Elsey, G.H. Fleet, P.B. Høj, I.S. Pretorius, and M.A. De Barros Lopes. 2005. Genetic determinants of volatile-thiol release by Saccharomyces cerevisiae during wine fermentation. Appl. Environ. Microbiol. 71:5420-5426.

Ilg, A., Q. J. Yu, P. Schaub, P. Beyer, and S. Al-Babili. 2010. Overexpression of the rice carotenoid cleavage dioxygenase 1 gene in Golden Rice endosperm suggests apocarotenoids as substrates in planta. Planta 232:691-699.

ISO. 1985. ISO 6564:1985 Sensory Analysis-Methodology-Flavour Profile. International Organization for Standardization, Geneva.

Iyer, M.M., G.L. Sacks, and O.I. Padilla-Zakour. 2010. Impact of harvesting and processing conditions on green leaf volatile development and phenolics in concord grape juice. J. Food Sci. 75:C297-C304.

Jaillon, O., et al. 2007. The grapevine genome sequence suggests ancestral hexaploidization in major angiosperm phyla. Nature 449:463-467.

Jakobsen, H.B., M. Hansen, M.R. Christensen, P.B. Brockhoff, and C.E. Olsen. 1998. Aroma volatiles of blanched green peas (Pisum sativum L.). J. Agric. Food Chem. 46:3727-3734.

Janusz, A., D.L. Capone, C.J. Puglisi, M.V. Perkins, G.M. Elsey, and M.A. Sefton. 2003. (E)-1-(2,3,6-Trimethylphenyl)buta-1,3-diene: A potent grape-derived odorant in wine. J. Agric. Food Chem. 51:7759-7763.

Jiranek, V., P. Langridge, and P.A. Henschke. 1995. Regulation of hydrogen sulfide liberation in wine-producing Saccharomyces cerevisiae strains by assimilable nitrogen. Appl. Environ. Microbiol. 61:461-467.

Kalua, C.M., and P.K. Boss. 2009. Evolution of volatile compounds during the development of Cabernet Sauvignon grapes (Vitis vinifera L.). J. Agric. Food Chem. 57:3818-3830.

Kalua, C.M., and P.K. Boss. 2010. Comparison of major volatile compounds from Riesling and Cabernet Sauvignon grapes (Vitis vinifera L.) from fruitset to harvest. Aust. J. Grape Wine Res. 16:337-348.

Karbowiak, T., R.D. Gougeon, J.B. Alinc, L. Brachais, F. Debeaufort, A. Voilley, and D. Chassagne. 2009. Wine oxidation and the role of cork. Crit. Rev. Food Sci. Nutr. 50:20-52.

Kennedy, J.A., M.A. Matthews, and A.L. Waterhouse. 2002. Effect of maturity and vine water status on grape skin and wine flavonoids. Am. J. Enol. Vitic. 53:268-274.

Kennison, K.R., M.R. Gibberd, A.P. Pollnitz, and K.L. Wilkinson. 2008. Smoke-derived taint in wine: The release of smoke-derived volatile phenols during fermentation of Merlot juice following grapevine exposure to smoke. J. Agric. Food Chem. 56:7379-7383.

Kennison, K.R., K.L. Wilkinson, H.G. Williams, J.H. Williams, and M.R. Gibberd. 2007. Smoke-derived taint in wine: Effect of postharvest smoke exposure of grapes on the chemical composition and sensory characteristics of wine. J. Agric. Food Chem. 55:10897-10901.

Keyzers, R.A., and P.K. Boss. 2010. Changes in the volatile compound production of fermentations made from musts with increasing grape content. J. Agric. Food Chem. 58:1153-1164.

King, E.S., I.L. Francis, J.H. Swiegers, and C. Curtin. 2011. Yeast strain-derived sensory differences retained in Sauvignon blanc wines after extended bottle storage. Am. J. Enol. Vitic. 62:366-370.
Klesk, K., and M. Qian. 2003. Aroma extract dilution analysis of cv. Marion (Rubus spp. hyb) and cv. Evergreen (R. laciniatus L.) blackberries. J. Agric. Food Chem. 51:3436-3441.

Klesk, K., M. Qian, and R.R. Martin. 2004. Aroma extract dilution analysis of cv. Meeker (Rubus idaeus L.) red raspberries from Oregon and Washington. J. Agric. Food Chem. 52:5155-5161.

Kliewer, W.M. 1968. Changes in the concentration of free amino acids in grape berries during maturation. Am. J. Enol. Vitic. 19:166-174.

Koch, A., C.L. Doyle, M.A. Matthews, L.E. Williams, and S.E. Ebeler. 2010. 2-Methoxy-3-isobutylpyrazine in grape berries and its dependence on genotype. Phytochemistry 71:2190-2198.

Koch, A., S.E. Ebeler, L.E. Williams, and M.A. Matthews. 2012. Fruit ripening in Vitis vinifera: Light intensity before and not during ripening determines the concentration of 2-methoxy-3-isobutylpyrazine in Cabernet Sauvignon berries. Physiol. Plant. 145:275-285.

Kotseridis, Y., and R. Baumes. 2000. Identification of impact odorants in Bordeaux red grape juice, in the commercial yeast used for its fermentation, and in the produced wine. J. Agric. Food Chem. 48:400-406.

Kotseridis, Y., A. Anocibar Beloqui, A. Bertrand, and J.P. Doazan. 1998. An analytical method for studying the volatile compounds of Merlot noir clone wines. Am. J. Enol. Vitic. 49:44-48.

Kotseridis, Y., R.L. Baumes, and G.K. Skouroumounis. 1999. Quantitative determination of free and hydrolytically liberated $\beta$-damascenone in red grapes and wines using a stable isotope dilution assay. J. Chromatogr., A 849:245-254.

Kumar, G.R., V. Ramakrishnan, and L.F. Bisson. 2010. Survey of hydrogen sulfide production in wine strains of Saccharomyces cerevisiae. Am. J. Enol. Vitic. 61:365-371.

Lacey, M.J., M.S. Allen, R.L.N. Harris, and W.V. Brown. 1991. Methoxypyrazines in Sauvignon blanc grapes and wines. Am. J. Enol. Vitic. 42:103-108.

Lairson, L.L., B. Henrissat, G.J. Davies, and S.G. Withers. 2008. Glycosyl transferases: Structures, functions, and mechanisms. Ann. Rev. Biochem. 77:521-555.

Lattey, K.A., B.R. Bramley, and I.L. Francis. 2010. Consumer acceptability, sensory properties and expert quality judgements of Australian Cabernet Sauvignon and Shiraz wines. Aust. J. Grape Wine Res. 16:189-202.

Lee, S.H., M.J. Seo, M. Riu, J.P. Cotta, D.E. Block, N.K. Dokoozlian, and S.E. Ebeler. 2007. Vine microclimate and norisoprenoid concentration in Cabernet Sauvignon grapes and wines. Am. J. Enol. Vitic. 58:291-301.

Lee, S.J., and A.C. Noble. 2003. Characterization of odor-active compounds in Californian Chardonnay wines using GC-olfactometry and GC-mass spectrometry. J. Agric. Food Chem. 51:8036-8044.

Lee, S.J., and A.C. Noble. 2006. Use of partial least squares regression and multidimensional scaling on aroma models of California Chardonnay wines. Am. J. Enol. Vitic. 57:363-370.

Linderholm, A.L., C.L. Findleton, G. Kumar, Y. Hong, and L.F. Bisson. 2008. Identification of genes affecting hydrogen sulfide formation in Saccharomyces cerevisiae. Appl. Environ. Microbiol. 74:1418-1427.

López-Rituerto, E., A. Avenoza, J.S.H. Busto, and J.S.M. Peregrina. 2010. Evidence of metabolic transformations of amino acids into higher alcohols through ${ }^{13} \mathrm{C}$ NMR studies of wine alcoholic fermentation. J. Agric. Food Chem. 58:4923-4927.

López, R., V. Ferreira, P. Hernández, and J.F. Cacho. 1999. Identification of impact odorants of young red wines made with Merlot, Cabernet Sauvignon and Grenache grape varieties: A comparative study. J. Sci. Food Agric. 79:1461-1467.

López, R., N. Ortín, J.P. Pérez-Trujillo, J. Cacho, and V. Ferreira. 2003. Impact odorants of different young white wines from the Canary Islands. J. Agric. Food Chem. 51:3419-3425. 
Lücker, J., P. Bowen, and J. Bohlmann. 2004. Vitis vinifera terpenoid cyclases: Functional identification of two sesquiterpene synthase cDNAs encoding $(+)$-valencene synthase and (-)-germacrene D synthase and expression of mono- and sesquiterpene synthases in grapevine flowers and berries. Phytochemistry 65:2649-2659.

Lund, S.T., and J. Bohlmann. 2006. The molecular basis for wine grape quality-A volatile subject. Science 311:804-805.

Maicas, S., and J.J. Mateo. 2005. Hydrolysis of terpenyl glycosides in grape juice and other fruit juices: A review. Appl. Microbiol, Biotechnol. 67:322-335.

Maletić, E., I. Pejić, J. Karoglan Kontić, J. Piljac, G.S. Dang1, A. Vokurka, T. Lacombe, N. Mirošević, and C.P. Meredith. 2004. Zinfandel, Dobričić, and Plavac mali: The genetic relationship among three cultivars of the Dalmatian Coast of Croatia. Am. J. Enol. Vitic. 55:174-180.

Marais, J. 1979. Effect of storage time and temperature on the formation of dimethyl sulphide and on white wine quality. Vitis 18:254-260.

Marais, J., and H. Pool. 1980. Effect of storage time and temperature on the volatile composition and quality of dry white table wines. Vitis 19:151-164.

Marais, J., G. Versini, C. Wyk, and A. Rapp. 1992. Effect of region on free and bound monoterpene and $\mathrm{C}_{13}$-norisoprenoid concentrations in Weisser Riesling wines. S. Afr. J. Enol. Vitic. 13:71-77.

Marais, J., C. Wyk, and A. Rapp. 1991. Carotenoid levels in maturing grapes as affected by climatic regions, sunlight and shade. S. Afr. J. Enol. Vitic. 12:64-69.

Martin, D.M., S. Aubourg, M.B. Schouwey, L. Daviet, M. Schalk, O. Toub, S.T. Lund, and J. Bohlmann. 2010. Functional annotation, genome organization and phylogeny of the grapevine (Vitis vinifera) terpene synthase gene family based on genome assembly, FLcDNA cloning, and enzyme assays. BMC Plant Biol. 10:226.

Martin, D.M., A. Chiang, S.T. Lund, and J. Bohlmann. 2012. Biosynthesis of wine aroma: Transcript profiles of hydroxymethylbutenyl diphosphate reductase, geranyl diphosphate synthase, and linalool/ nerolidol synthase parallel monoterpenol glycoside accumulation in Gewürztraminer grapes. Planta 236:919-929.

Mason, A.B., and J.P. Dufour. 2000. Alcohol acetyltransferases and the significance of ester synthesis in yeast. Yeast 16:1287-1298.

Masson, G., and R. Schneider. 2009. Key compounds of Provence rosé wine flavor. Am. J. Enol. Vitic. 60:116-122.

Mateo, J.J., and M. Jimeńez. 2000. Monoterpenes in grape juice and wines. J. Chromatogr., A 881:557-567.

Mathieu, S., N. Terrier, J. Procureur, F. Bigey, and Z. Günata. 2005. A carotenoid cleavage dioxygenase from Vitis vinifera L.: Functional characterization and expression during grape berry development in relation to $\mathrm{C}_{13}$-norisoprenoid accumulation. J. Exp. Bot. 56:2721-2731.

Mathieu, S., J. Wirth, F.X. Sauvage, J.P. Lepoutre, R. Baumes, and Z. Günata. 2009. Biotransformation of $\mathrm{C}_{13}$-norisoprenoids and monoterpenes by a cell suspension culture of cv. Gamay (Vitis vinifera). Plant Cell Tiss. Organ Cult. 97:203-213.

Mazida, M.M., M.M. Salleh, and H. Osman. 2005. Analysis of volatile aroma compounds of fresh chilli (Capsicum annuum) during stages of maturity using solid phase microextraction (SPME). J. Food Comp. Anal. 18:427-437.

Mendes-Pinto, M.M. 2009. Carotenoid breakdown products the-norisoprenoids-in wine aroma. Arch. Biochem. Biophys. 483:236-245.

Mendes-Pinto, M.M., A.C. Silva Ferreira, C. Caris-Veyrat, and P. Guedes de Pinho. 2005. Carotenoid, chlorophyll, and chlorophyllderived compounds in grapes and port wines. J. Agric. Food Chem. 53:10034-10041

Mestres, M., O. Busto, and J. Guasch. 2000. Analysis of organic sulfur compounds in wine aroma. J. Chromatogr., A 881:569-581.
Mestres, M., O. Busto, and J. Guasch. 2002. Application of headspace solid-phase microextraction to the determination of sulphur compounds with low volatility in wines. J. Chromatogr., A 945:211-219.

Miklósy, E., and Z. Kerényi. 2004. Comparison of the volatile aroma components in noble rotted grape berries from two different locations of the Tokaj wine district in Hungary. Anal. Chim. Acta 513:177-181.

Miller, A.C., S.R. Wolff, L.F. Bisson, and S.E. Ebeler. 2007. Yeast strain and nitrogen supplementation: Dynamics of volatile ester production in Chardonnay juice fermentations. Am. J. Enol. Vitic. 58:470-483.

Mira de Orduña, R. 2010. Climate change associated effects on grape and wine quality and production. Food Res. Int. 43:1844-1855.

Moio, L., and P.X. Etievant. 1995. Ethyl anthranilate, ethyl cinnamate, 2,3-dihydrocinnamate, and methyl anthranilate: Four important odorants identified in Pinot noir wines of Burgundy. Am. J. Enol. Vitic. 46:392-398.

Molina, A., J. Swiegers, C. Varela, I. Pretorius, and E. Agosin. 2007. Influence of wine fermentation temperature on the synthesis of yeast-derived volatile aroma compounds. Appl. Microbiol. Biotechnol. 77:675-687.

Moreira, N., F. Mendes, O. Pereira, P. Guedes de Pinho, T. Hogg, and I. Vasconcelos. 2002. Volatile sulphur compounds in wines related to yeast metabolism and nitrogen composition of grape musts. Anal. Chim. Acta 458:157-167.

Mori, K., H. Nagao, and Y. Yoshihara. 1999. The olfactory bulb: Coding and processing of odor molecule information. Science 286:711-715.

Murat, M.L., T. Tominaga, and D. Dubourdieu. 2001. Assessing the aromatic potential of Cabernet Sauvignon and Merlot musts used to produce rose wine by assaying the cysteinylated precursor of 3-mercaptohexan-1-ol. J. Agric. Food Chem. 49:5412-5417.

Nair, N.G. 1985. Fungi associated with bunch rot of grapes in the Hunter Valley. Aust. J. Agric. Res. 36:435-442.

Neta, E.R.D., R.E. Miracle, T.H. Sanders, and M.A. Drake. 2008. Characterization of alkylmethoxypyrazines contributing to earthy/bell pepper flavor in farmstead cheddar cheese. J. Food Sci. 73:C632-C638.

Newman, J.D., and J. Chappell. 1999. Isoprenoid biosynthesis in plants: Carbon partitioning within the cytoplasmic pathway. Crit. Rev. Biochem. Mol. Biol. 34:95-106.

Noble, A.C., and S.E. Ebeler. 2002. Use of multivariate statistics in understanding wine flavor. Food Rev. Int. 18:1-21.

Noble, A.C., R.A. Flath, and R.R. Forrey. 1980. Wine headspace analysis. Reproducibility and application to varietal classification. J. Agric. Food Chem. 28:346-353.

Offen, W., C. Martinez-Fleites, M. Yang, E. Kiat-Lim, B.G. Davis, C.A. Tarling, C.M. Ford, D.J. Bowles, and G.J. Davies. 2006. Structure of a flavonoid glucosyltransferase reveals the basis for plant natural product modification. EMBO J. 25:1396-1405.

Ohloff, G. 1978. Importance of minor components in flavors and fragrances. Perfum. Flav. 3:11-22.

Oliveira, C., A.C. Silva Ferreira, M. Mendes Pinto, T. Hogg, F. Alves, and P. Guedes de Pinho. 2003. Carotenoid compounds in grapes and their relationship to plant water status. J. Agric. Food Chem. 51:5967-5971.

Ong, P.K.C., and T.E. Acree. 1999. Similarities in the aroma chemistry of Gewurztraminer variety wines and lychee (Litchi chinesis Sonn.) fruit. J. Agric. Food Chem. 47:665-670.

Ono, B.I., T. Hazu, S. Yoshida, T. Kawato, S. Shinoda, J. Brzvwczy, and A. Paszewski. 1999. Cysteine biosynthesis in Saccharomyces cerevisiae: A new outlook on pathway and regulation. Yeast 15:1365-1375.

Ono, B.I., K. Kijima, N. Ishii, T. Kawato, A. Matsuda, A. Paszewski, and S. Shinoda. 1996. Regulation of sulphate assimilation in Saccharomyces cerevisiae. Yeast 12:1153-1162. 
Ono, E., Y. Homma, M. Horikawa, S. Kunikane-Doi, H. Imai, S. Takahashi, Y. Kawai, M. Ishiguro, Y. Fukui, and T. Nakayama. 2010. Functional differentiation of the glycosyltransferases that contribute to the chemical diversity of bioactive flavonol glycosides in grapevines (Vitis vinifera). Plant Cell 22:2856-2871.

Orlova, I., et al. 2006. Reduction of benzenoid synthesis in petunia flowers reveals multiple pathways to benzoic acid and enhancement in auxin transport. Plant Cell 18:3458-3475.

Oruna-Concha, M.J., S.C. Duckham, and J.M. Ames. 2001. Comparison of volatile compounds isolated from the skin and flesh of four potato cultivars after baking. J. Agric. Food Chem. 49:2414-2421.

Ou, C., X. Du, K. Shellie, C. Ross, and M.C. Qian. 2010. Volatile compounds and sensory attirbutes of wine from cv. Merlot (Vitis vinifera L.) grown under differential levels of water deficit with or without a kaolin-based foliar reflectant particle film. J. Agric Food Chem. 58:12890-12898.

Ough, C.S. 1985. Some effects of temperature and $\mathrm{SO}_{2}$ on wine during simulated transport or storage. Am. J. Enol. Vitic. 36:18-22.

Parker, M., A.P. Pollnitz, D. Cozzolino, I.L. Francis, and M.J. Herderich. 2007. Identification and quantification of a marker compound for 'pepper' aroma and flavor in Shiraz grape berries by combination of chemometrics and gas chromatography-mass spectrometry. J. Agric. Food Chem. 55:5948-5955.

Peña-Gallego, A., P. Hernández-Orte, J. Cacho, and V. Ferreira. 2012. $S$-Cysteinylated and $S$-glutathionylated thiol precursors in grapes. A review. Food Chem. 131:1-13.

Pérez-Coello, M.S., M.A. González-Viñas, E. García-Romero, M.C. Díaz-Maroto, and M.D. Cabezudo. 2003. Influence of storage temperature on the volatile compounds of young white wines. Food Control 14:301-306.

Perot des Gachons, C., C. van Leeuwen, T. Tominaga, J.P. Soyer, J.P. Gaudillère, and D. Dubourdieu. 2005. Influence of water and nitrogen deficit on fruit ripening and aroma potential of Vitis vinifera L. cv. Sauvignon blanc in field conditions. J. Sci. Food Agric. 85:73-85.

Perot des Gachons, C., T. Tominaga, and D. Dubourdieu. 2000. Measuring the aromatic potential of Vitis vinifera L. cv. Sauvignon blanc grapes by assaying $S$-cysteine conjugates, precursors of the volatile thiols responsible for their varietal aroma. J. Agric. Food Chem. 48:3387-3391.

Pickering, G., J. Lin, R. Riesen, A. Reynolds, I. Brindle, and G. Soleas. 2004. Influence of Harmonia axyridis on the sensory properties of white and red wine. Am. J. Enol. Vitic. 55:153-159.

Piggott, J.R. 1990. Relating sensory and chemical data to understand flavor. J. Sens. Stud. 4:261-272.

Pineau, B., J.C. Barbe, C. Van Leeuwen, and D. Dubourdieu. 2007. Which impact for $\beta$-damascenone on red wines aroma? J. Agric. Food Chem. 55:4103-4108.

Pineau, B., J.C. Barbe, C. Van Leeuwen, and D. Dubourdieu. 2009. Examples of perceptive interactions involved in specific "red-" and "black-berry" aromas in red wines. J. Agric. Food Chem. 57:37023708.

Polášková, P., J. Herszage, and S.E. Ebeler. 2008. Wine flavor: Chemistry in a glass. Chem. Soc. Rev. 37:2478-2489.

Pons, A., V. Lavigne, F. Eric, P. Darriet, and D. Dubourdieu. 2008. Identification of volatile compounds responsible for prune aroma in prematurely aged red wines. J. Agric. Food Chem. 56:5285-5290.

Pons, A., V.R. Lavigne, Y. Landais, P. Darriet, and D. Dubourdieu. 2010. Identification of a sotolon pathway in dry white wines. J. Agric. Food Chem. 58:7273-7279.

Power, F.B., and V.K. Chesnut. 1921. The occurrence of methyl anthranilate in grape juice. J. Am. Chem. Soc. 43:1741-1742.
Pozo-Bayón, M.A., E.G. Alegría, M.C. Polo, C. Tenorio, P.J. MartínÁlvarez, M.T. Calvo de la Banda, F. Ruiz-Larrea, and M.V. MorenoArribas. 2005. Wine volatile and amino acid composition after malolactic fermentation: Effect of Oenococcus oeni and Lactobacillus plantarum starter cultures. J. Agric. Food Chem. 53:8729-8735.

Prida, A., and P. Chatonnet. 2010. Impact of oak-derived compounds on the olfactory perception of barrel-aged wines. Am. J. Enol. Vitic. 61:408-413.

Qian, M., and T.H. Shellhammer (eds.). 2012. Flavor Chemistry of Wine and Other Alcoholic Beverages. ACS Symp. Series 1104. Am. Chemical Society, Washington, DC.

Qualley, A.V, J.R. Widhalm, F. Adebesin, C.M. Kish, and N. Dudareva. 2012. Completion of the core $\beta$-oxidative pathway of benzid acid biosynthesis in plants. Proc. Natl. Acad. Sci. 109:16383-16388.

Raab, T., J.A. López-Ráez, D. Klein, J.L. Caballero, E. Moyano, W. Schwab, and J. Muñoz-Blanco. 2006. FaQR, required for the biosynthesis of the strawberry flavor compound 4-hydroxy-2,5dimethyl-2(2H)-furanone, encodes an enone oxidoreductase. Plant Cell 18:1023-1037.

Raguso, R.A., and E. Pichersky. 1999. A day in the life of a linalool molecule: Chemical communication in a plant-pollinator system. Part 1: Linalool biosynthesis in flowering plants. Plant Species Biol. 14:95-120.

Ramey, D.D., and C.S. Ough. 1980. Volatile ester hydrolysis or formation during storage of model solutions and wines. J. Agric. Food Chem. 28:928-934.

Rapp, A. 1998a. Wine aroma substances from gas chromatographic analysis. In Wine Analysis. H.F. Linskens and J.F. Jackson (eds.), pp. 29-66. Springer-Verlag, Berlin.

Rapp, A. 1998b. Volatile flavour of wine: Correlation between instrumental analysis and sensory perception. Nahrung 42:351-363.

Rapp, A., and H. Mandery. 1986. Wine aroma. Experientia 42:873-884.

Rapp, A., W. Knipser, L. Engel, H. Ullemeyer, and W. Heimann. 1980. Off-flavour compounds in the berry and wine aroma of grapevine hybrids I. The strawberry-like flavour. Vitis 19:13-23.

Rauhut, D. 2009. Usage and formation of sulphur compounds. In Biology of Microorganisms on Grapes, in Must and in Wine. H. König et al. (eds.), pp. 181-207. Springer-Verlag, Berlin.

Rauhut, D., and H. Körbel. 1994. The production of $\mathrm{H}_{2} \mathrm{~S}$ from elemental sulfur residues during fermentation and its influence on the formation of sulfur metabolites causing off-flavors in wines. Vitic. Enol. Sci. (Wein-Wissensch.) 49:27-36.

Rauhut, D., H. Körbel, H. H. Dittrich, and M. Grossmann. 1996. Properties and differences of commercial yeast strains with respect to their formation of sulfur compounds. Vitic. Enol. Sci. (WeinWissensch.) 51:187-192.

Razungles, A.J., I. Babic, J.C. Sapis, and C.L. Bayonove. 1996. Particular behavior of epoxy xanthophylls during veraison and maturation of grape. J. Agric. Food Chem. 44:3821-3825.

Razungles, A., C.L. Bayonove, R.E. Cordonnier, and J.C. Sapis. 1988. Grape carotenoids: Changes during the maturation period and localization in mature berries. Am. J. Enol. Vitic. 39:44-48.

Razungles, A., Z. Günata, S. Pinatel, R. Baumes, and C. Bayonove. 1993. Quantitative studies on terpenes, norisoprenoids and their precursors in several varieties of grapes. Sci. Aliments 13:59-72.

Reynolds, A.G., and D.A. Wardle. 1989. Influence of fruit microclimate on monoterpene levels of Gewurztraminer. Am. J. Enol. Vitic. 40:149-154.

Reynolds, A., M. Cliff, B. Girard, and T.G. Kopp. 2001. Influence of fermentation temperature on composition and sensory properties of Semillon and Shiraz wines. Am. J. Enol. Vitic. 52:235-240. 
Ribéreau-Gayon, P. 1974. The Chemistry of Red Wine Color. In Chemistry of Winemaking. A.D. Webb (ed.), pp. 50-87. Advances in Chemistry 137. Am. Chemical Society, Washington, DC.

Ribéreau-Gayon, P., J.N. Boidron, and A. Terrier. 1975. Aroma of Muscat grape varieties. J. Agric. Food Chem. 23:1042-1047.

Richter, C.L., B. Dunn, G. Sherlock, and T. Pugh. 2013. Comparative metabolic footprinting of a large number of commercial wine yeast strains in Chardonnay fermentations. FEMS Yeast Res. 13:394-410.

Robinson, A.L., P.K. Boss, H. Heymann, P.S. Solomon, and R.D. Trengove. 2011. Influence of yeast strain, canopy management, and site on the volatile composition and sensory attributes of Cabernet Sauvignon wines from western Australia. J. Agric. Food Chem. 59:3273-3284.

Robinson, A.L., S.E. Ebeler, H. Heymann, P.K. Boss, P.S. Solomon, and R.D. Trengove. 2009. Interactions between wine volatile compounds and grape and wine matrix components influence aroma compound headspace partitioning. J. Agric. Food Chem. 57:10313-10322.

Rocha, S.M., E. Coelho, J. Zrostlíková, I. Delgadillo, and M.A. Coimbra. 2007. Comprehensive two-dimensional gas chromatography with time-of-flight mass spectrometry of monoterpenoids as a powerful tool for grape origin traceability. J. Chromatogr., A 1161:292-299.

Rohmer, M. 1999. The discovery of a mevalonate-independent pathway for isoprenoid biosynthesis in bacteria, algae and higher plants. Nat. Prod. Rep. 16:565-574.

Roland, A., R. Schneider, F. Charrier, F. Cavelier, M. Rossignol, and A. Razungles. 2011. Distribution of varietal thiol precursors in the skin and the pulp of Melon B. and Sauvignon blanc grapes. Food Chem. 125:139-144.

Roland, A., R. Schneider, C.L. Guernevé, A. Razungles, and F. Cavelier. 2010. Identification and quantification by LC-MS/MS of a new precursor of 3-mercaptohexan-1-ol (3MH) using stable isotope dilution assay: Elements for understanding the $3 \mathrm{MH}$ production in wine. Food Chem. 121:847-855.

Romano, A., M.C. Perello, A. Lonvaud-Funel, G. Sicard, and G. de Revel. 2009. Sensory and analytical re-evaluation of "Brett character." Food Chem. 114:15-19.

Roncoroni, M., M. Santiago, D.O. Hooks, S. Moroney, M.J. Harsch, S.A. Lee, K.D. Richards, L. Nicolau, and R.C. Gardner. 2011. The yeast IRC7 gene encodes a $\beta$-lyase responsible for production of the varietal thiol 4-mercapto-4-methylpentan-2-one in wine. Food Microbiol. 28:926-935.

Rosillo, L., M.A.R. Salinas, J. Garijo, and G.L. Alonso. 1999. Study of volatiles in grapes by dynamic headspace analysis: Application to the differentiation of some Vitis vinifera varieties. J. Chromatogr., A 847:155-159.

Rossouw, D., T. Næs, and F.F. Bauer. 2008. Linking gene regulation and the exo-metabolome: A comparative transcriptomics approach to identify genes that impact on the production of volatile aroma compounds in yeast. BMC Genomics 9:530. 10.1186/1471-2164-9-530.

Rossouw, D., R. Olivares-Hernandes, J. Nielsen, and F.F. Bauer. 2009. Comparative transcriptomic approach to investigate differences in wine yeast physiology and metabolism during fermentation. Appl. Environ. Microbiol. 75:6600-6612.

Roujou de Boubée, D., A.M. Cumsille, M. Pons, and D. Dubourdieu. 2002. Location of 2-methoxy-3-isobutylpyrazine in Cabernet Sauvignon grape bunches and its extractability during vinification. Am. J. Enol. Vitic. 53:1-5.

Roujou de Boubée, D., C. Van Leeuwen, and D. Dubourdieu. 2000. Organoleptic impact of 2-methoxy-3-isobutylpyrazine on red Bordeaux and Loire wines. Effect of environmental conditions on concentrations in grapes during ripening. J. Agric. Food Chem. 48:4830-4834.

Rubio, A., J.J. Rambla, M. Santaella, M.D. Gómez, D. Orzaez, A. Granell, and L. Gómez-Gómez. 2008. Cytosolic and plastoglobule targeted carotenoid dioxygenases from Crocus sativus are both involved in $\beta$-ionone-release. J. Biol. Chem. 283:24816-24825.
Ruffner, H.P. 1982a. Metabolism of tartaric and malic acids in Vitis: A review, Part A. Vitis 21:247-259.

Ruffner, H.P. 1982b. Metabolism of tartaric and malic acids in Vitis: A review, Part B. Vitis 21:346-358.

Ruyter-Spira, C., S. Al-Babili, S. van der Krol, and H. Bouwmeester. 2013. The biology of strigolactones. Trends Plant Sci. 18:72-83.

Ryona, I., B.S. Pan, D.S. Intrigliolo, A.N. Lakso, and G.L. Sacks. 2008. Effects of cluster light exposure on 3-isobutyl-2-methoxypyrazine accumulation and degradation patterns in red wine grapes (Vitis vinifera L. vv. Cabernet franc). J. Agric. Food Chem. 56:10838-10846.

Sacchi, K.L., L.F. Bisson, and D.O. Adams. 2005. A review of the effect of winemaking techniques on phenolic extraction in red wines. Am. J. Enol. Vitic. 56:197-206.

Sadras, V.O., M.A. Moran, and M. Bonada. 2013. Effects of elevated temperature in grapevine. I. Berry sensory traits. Aust. J. Grape Wine Res. 19:95-106.

Sáenz-Navajas, M.P., E. Campo, L. Culleré, P. Fernández-Zurbano, D. Valentin, and V. Ferreira. 2010. Effects of the nonvolatile matrix on the aroma perception of wine. J. Agric. Food Chem. 58:5574-5585.

Sáenz-Navajas, M.P., P. Fernández-Zurbano, and V. Ferreira. 2012. Contribution of nonvolatile composition to wine flavor. Food Rev. Int. 28:389-411.

Saerens, S.M.G., F.R. Delvaux, K.J. Verstrepen, and J.M. Thevelein. 2010. Production and biological function of volatile esters in Saccharomyces cerevisiae. Microbial Biotech. 3:165-177.

Saerens, S.M.G., F. Delvaux, K.J. Verstrepen, P. Van Dijck, J.M. Thevelein, and F.R. Delvaux. 2008. Parameters affecting ethyl ester production by Saccharomyces cerevisiae during fermentation. Appl. Environ. Microbiol. 74:454-461.

Saerens, S.M.G., K.J. Verstrepen, S.D.M. Van Laere, A.R.D. Voet, P. Van Dijck, F.R. Delvaux, and J.M. Thevelein. 2006. The Saccharomyces cerevisiae EHT1 and EEBI genes encode novel enzymes with medium-chain fatty acid ethyl ester synthesis and hydrolysis capacity. J. Biol. Chem. 281:4446-4456.

Sala, C., O. Busto, J. Guasch, and F. Zamora. 2004. Influence of vine training and sunlight exposure on the 3-alkyl-2-methoxypyrazines content in musts and wines from the Vitis vinifera variety Cabernet Sauvignon. J. Agric. Food Chem. 52:3492-3497.

Sala, C., M. Mestres, M.P. Marti, O. Busto, and J. Guasch. 2000. Headspace solid-phase microextraction method for determining 3-alkyl-2- methoxypyrazines in musts by means of polydimethylsiloxane-divinylbenzene fibres. J. Chromatogr., A 880:93-99.

Sarrazin, E., D. Dubourdieu, and P. Darriet. 2007a. Characterization of key-aroma compounds of botrytized wines, influence of grape botrytization. Food Chem. 103:536-545.

Sarrazin, E., S. Shinkaruk, T. Tominaga, B. Bennetau, E. Frérot, and D. Dubourdieu. 2007b. Odorous impact of volatile thiols on the aroma of young botrytized sweet wines: Identification and quantification of new sulfanyl alcohols. J. Agric. Food Chem. 55:1437-1444.

Scheele, C.W., and C.P.G. De Morveau. 2009. Mémoires De Chymie, Parts 1-2 (1785). Kessinger Publishing, Whitefish, Montana.

Scheiner, J.J., G.L. Sacks, B. Pan, S. Ennahli, L. Tarlton, A. Wise, S.D. Lerch, and J.E. Vanden Heuvel. 2010. Impact of severity and timing of basal leaf removal on 3-isobutyl-2-methoxypyrazine concentrations in red winegrapes. Am. J. Enol. Vitic. 61:358-364.

Schieberle, P., and T. Hofmann. 1997. Evaluation of the character impact odorants in fresh strawberry juice by quantitative measurements and sensory studies on model mixtures. J. Agric. Food Chem. 45:227-232.

Schiefner, A., Q. Sinz, I. Neumaier, W. Schwab, and A. Skerra. 2013. Structural basis for the enzymatic formation of the key straberry flavor compounds 4-hydroxy-2,5-dimethyl-3(2H)-furanone. J. Biol. Chem. 288:16815-16826. 
Schneider, R., A. Razungles, C. Augier, and R. Baumes. 2001. Monoterpenic and norisoprenoidic glycoconjugates of Vitis vinifera $\mathrm{L}$. cv. Melon B. as precursors of odorants in Muscadet wines. J. Chromatogr., A 936:145-157.

Schneider, R., A. Razungles, F. Charrier, and R. Baumes. 2002. The effect of the site, maturity and lighting of grape bunches on the aromatic composition of Vitis vinifera L. cv. Melon B. berries in Muscadet vineyards. Bull. OIV 75:269-282.

Schoch, E., I. Benda, and P. Schreier. 1991. Bioconversion of $\alpha$-damascone by Botrytis cinerea. Appl. Environ. Microbiol. 57:15-18.

Schreier, P., F. Drawert, and A. Junker. 1976. Identification of volatile constituents from grapes. J. Agric. Food Chem. 24:331-336.

Schultz, H. 2000. Climate change and viticulture: A European perspective on climatology, carbon dioxide and UV-B effects. Aust. J. Grape Wine Res. 6:2-12.

Schütz, M., and R.E. Kunkee. 1977. Formation of hydrogen sulfide from elemental sulfur during fermentation by wine yeast. Am. J. Enol. Vitic. 28:137-144.

Schwab, W., R. Davidovich-Rikanati, and E. Lewinsohn. 2008. Biosynthesis of plant-derived flavor compounds. Plant J. 54:712-732.

Sea, K., C. Butzke, and R. Boulton. 1998. Seasonal variation in the production of hydrogen sulfide during wine fermentations. In Chemistry of Wine Flavor. A.L. Waterhouse and S.E. Ebeler (eds.), pp. 81-95. ACS Symp. Series 714. Am. Chemical Society, Washington, DC.

Sefton, M.A, G.K. Skouroumounis, G.M. Elsey, and D.K. Taylor. 2011. Occurrence, sensory impact, formation, and fate of damascenone in grapes, wines, and other foods and beverages. J. Agric. Food Chem. 59:9717-9746.

Sefton, M.A. 1998. Hydrolytically-released volatile secondary metabolites from a juice sample of Vitis vinifera grape cvs. Merlot and Cabernet Sauvignon. Aust. J. Grape Wine Res. 4:30-38.

Sefton, M.A., and P.J. Williams. 1991. Generation of oxidation artifacts during the hydrolysis of norisoprenoid glycosides by fungal enzyme preparations. J. Agric. Food Chem. 39:1994-1997.

Sefton, M.A., I.L. Francis, and P.J. Williams. 1990. Volatile norisoprenoid compounds as constituents of oak woods used in wine and spirit maturation. J. Agric. Food Chem. 38:2045-2049.

Sefton, M.A., I.L. Francis, and P.J. Williams. 1993. The volatile composition of Chardonnay juices: A study by flavor precursor analysis. Am. J. Enol. Vitic. 44:359-370.

Sefton, M.A., I.L. Francis, and P.J. Williams. 1994. Free and bound volatile secondary metabolites of Vitis vinifera grape cv. Sauvignon blanc. J. Food Sci. 59:142-147.

Sefton, M.A., I.L. Francis, and P.J. Williams. 1996. The free and bound volatile secondary metabolites of Vitis vinifera grape cv. Semillon. Aust. J. Grape Wine Res. 2:179-183.

Segurel, M.A., A.J. Razungles, C. Riou, M. Salles, and R.L. Baumes. 2004. Contribution of dimethyl sulfide to the aroma of Syrah and Grenache noir wines and estimation of its potential in grapes of these varieties. J. Agric. Food Chem. 52:7084-7093.

Shao, H., X. He, L. Achnine, J.W. Blount, R.A. Dixon, and X. Wang. 2005. Crystal structures of a multifunctional triterpene/flavonoid glycosyltransferase from Medicago truncatula. Plant Cell 17:3141-3154.

Shepherd, G.M. 2006. Smell images and the flavour system in the human brain. Nature 444:316-321.

Shepherd, G.M. 2007. Perspectives on olfactory processing, conscious perception, and orbitofrontal cortex. Ann. N.Y. Acad. Sci. 1121:87-101.

Siebert, T.E., C. Wood, G.M. Elsey, and A.P. Pollnitz. 2008. Determination of rotundone, the pepper aroma impact compound, in grapes and wine. J. Agric. Food Chem. 56:3745-3748.

Silva Ferreira, A.C., and P. Guedes de Pinho. 2004. Nor-isoprenoids profile during port wine ageing: Influence of some technological parameters. Anal. Chim. Acta 513:169-176.
Silva Ferreira, A.C., P. Guedes de Pinho, P. Rodrigues, and T. Hogg. 2002. Kinetics of oxidative degradation of white wines and how they are affected by selected technological parameters. J. Agric. Food Chem. 50:5919-5924.

Simpson, R. 1979. Aroma composition of bottle aged white wine. Vitis 18:148-154.

Simpson, R.F. 1978. Aroma and compositional changes in wine with oxidation, storage and aging. Vitis 17:274-287.

Singh, R., S. Rastogi, and U.N. Dwivedi. 2010. Phenylpropanoid metabolism in ripening fruits. Compr. Rev. Food Sci. Food Safety 9:398-416.

Sirikantaramas, S., M. Yamazaki, and K. Saito. 2008. Mechanisms of resistance to self-produced toxic secondary metabolites in plants. Phytochem. Rev. 7:467-477.

Skinkis, P.A., B.P. Bordelon, and E.M. Butz. 2010. Effects of sunlight exposure on berry and wine monoterpenes and sensory characteristics of Traminette. Am. J. Enol. Vitic. 61:147-156.

Skouroumounis, G.K., and M.A. Sefton. 2000. Acid-catalyzed hydrolysis of alcohols and their $\beta$-D-glucopyranosides. J. Agric. Food Chem. 48:2033-2039.

Skouroumounis, G., and M. Sefton. 2002. The formation of $\beta$-damascenone in wine. In Carotenoid-Derived Aroma Compounds. P. Winterhalter and R. Rouseff (eds.), pp. 241-254. ACS Symp. Series 802. Am. Chemical Society, Washington, DC.

Spillman, P.J., M.A. Sefton, and R. Gawel. 2004a. The contribution of volatile compounds derived during oak barrel maturation to the aroma of a Chardonnay and Cabernet Sauvignon wine. Aust. J. Grape Wine Res. 10:227-235.

Spillman, P.J., M.A. Sefton, and R. Gawel. 2004b. The effect of oak wood source, location of seasoning and coopering on the composition of volatile compounds in oak-matured wines. Aust. J. Grape Wine Res. 10:216-226.

Spiropoulos, A., and L.F. Bisson. 2000. MET17 and hydrogen sulfide formation in Saccharomyces cerevisiae. Appl. Environ. Microbiol. 66:4421-4426.

Stahl-Biskup, E., F. Intert, J. Holthuijzen, M. Stengele, and G. Schulz. 1993. Glycosidically bound volatiles: A review 1986-1991. Flavour Frag. J. 8:61-80

Steinhaus, M., D. Sinuco, J. Polster, C. Osorio, and P. Schieberle. 2009. Characterization of the key aroma compounds in pink guava (Psidium guajava L.) by means of aroma re-engineering experiments and omission tests. J. Agric. Food Chem. 57:2882-2888.

Stines, A.P., J. Grubb, H. Gockowiak, P.A. Henschke, P.B. Høj, and R. van Heeswijck. 2000. Proline and arginine accumulation in developing berries of Vitis vinifera L. in Australian vineyards: Influence of vine cultivar, berry maturity and tissue type. Aust. J. Grape Wine Res. 6:150-158

Stitt, M., R. Sulpice, and J. Keurentjes. 2010. Metabolic networks: How to identify key components in the regulation of metabolism and growth? Plant Physiol. 152:428-444.

Strauss, C.R., B. Wilson, R. Anderson, and P.J. Williams. 1987. Development of precursors of $\mathrm{C}_{13}$ nor-isoprenoid flavorants in Riesling grapes. Am. J. Enol. Vitic. 38:23-27.

Styger, G., B. Prior, and F.F. Bauer. 2011. Wine flavor and aroma. J. Ind. Microbiol Biotechnol. 38:1145-1159.

Suárez, R., J.A. Suárez-Lepe, A. Morata, and F. Calderón. 2007. The production of ethylphenols in wine by yeasts of the genera Brettanomyces and Dekkera: A review. Food Chem. 102:10-21.

Subileau, M., R.M. Schneider, J.M. Salmon, and E. Degryse. 2008. New insights on 3-mercaptohexanol $(3 \mathrm{MH})$ biogenesis in Sauvignon blanc wines: Cys-3MH and $(E)$-hexen-2-al are not the major precursors. J. Agric. Food Chem. 56:9230-9235. 
Sumby, K.M., P.R. Grbin, and V. Jiranek. 2010. Microbial modulation of aromatic esters in wine: Current knowledge and future prospects. Food Chem. 121:1-16.

Sweetman, C., L.G. Deluc, G.R. Cramer, C.M. Ford, and K.L. Soole. 2009. Regulation of malate metabolism in grape berry and other developing fruits. Phytochemistry 70:1329-1344.

Swiegers, J., and I. Pretorius. 2007. Modulation of volatile sulfur compounds by wine yeast. Appl. Microbiol. Biotechnol. 74:954-960.

Swiegers, J.H., D.L. Capone, K.H. Pardon, G.M. Elsey, M.A. Sefton, I.L. Francis, and I.S. Pretorius. 2007. Engineering volatile thiol release in Saccharomyces cerevisiae for improved wine aroma. Yeast 24:561-574.

Swiegers, J.H., E.J. Bartowsky, P.A. Henschke, and I.S. Pretorius. 2005a. Yeast and bacterial modulation of wine aroma and flavour. Aust. J. Grape Wine Res. 11:139-173.

Swiegers, J.H., P.J. Chambers, and I.S. Pretorius. 2005b. Olfaction and taste: Human perception, physiology and genetics. Aust. J. Grape Wine Res. 11:109-113.

Taylor, A.J. 1998. Physical chemistry of flavour. Int. J. Food Sci. Technol. 33:53-62.

Tehlivets, O., K. Scheuringer, and S.D. Kohlwein. 2007. Fatty acid synthesis and elongation in yeast. Biochim. Biophys. Acta Mol. Cell Biol. Lipids 1771:255-270.

Thibon, C., S. Shinkaruk, M. Jourdes, B. Bennetau, D. Dubourdieu, and T. Tominaga. 2010. Aromatic potential of botrytized white grapes: Identification and quantification of new cysteine- $S$-conjugate flavor precursors. Anal. Chim. Acta 660:190-196.

Tokitomo, Y., M. Steinhaus, A. Büttner, and P. Schieberle. 2005. Odor-active constituents in fresh pineapple (Ananas comosus [L.] Merr.) by quantitative and sensory evaluation. Biosci. Biotech. Biochem. 69:1323-1330.

Tominaga, T., and D. Dubourdieu. 2006. A novel method for quantification of 2-methyl-3-furanthiol and 2-furanmethanethiol in wines made from Vitis vinifera grape varieties. J. Agric. Food Chem. 54:29-33.

Tominaga, T., R. Baltenweck-Guyot, C. Perot des Gachons, and D. Dubourdieu. 2000a. Contribution of volatile thiols to the aromas of white wines made from several Vitis vinifera grape varieties. Am. J. Enol. Vitic. 51:178-181.

Tominaga, T., L. Blanchard, P. Darriet, and D. Dubourdieu. 2000b. A powerful aromatic volatile thiol, 2-furanmethanethiol, exhibiting roast coffee aroma in wines made from several Vitis vinifera grape varieties. J. Agric. Food Chem. 48:1799-1802.

Tominaga, T., A. Furrer, R. Henry, and D. Dubourdieu. 1998. Identification of new volatile thiols in the aroma of Vitis vinifera L. var. Sauvignon blanc wines. Flavour Frag. J. 13:159-162.

Torrens, J., P. Urpí, M. Riu-Aumatell, S. Vichi, E. López-Tamames, and S. Buxaderas. 2008. Different commercial yeast strains affecting the volatile and sensory profile of cava base wine. Int. J. Food Microbiol. 124:48-57.

Ugliano, M. 2009. Enzymes in winemaking. In Wine Chemistry and Biochemistry. M.V. Moreno-Arribas and M.C. Polo (eds.), pp. 103126. Springer, New York.

Ugliano, M., and L. Moio. 2005. Changes in the concentration of yeast-derived volatile compounds of red wine during malolactic fermentation with four commercial starter cultures of Oenococcus oeni. J. Agric. Food Chem. 53:10134-10139.

Ugliano, M., E.J. Bartowsky, J. McCarthy, L. Moio, and P.A. Henschke. 2006. Hydrolysis and transformation of grape glycosidically bound volatile compounds during fermentation with three Saccharomyces yeast strains. J. Agric. Food Chem. 54:6322-6331.

Ugliano, M., M. Kwiatkowski, S. Vidal, D.L. Capone, M.R. Solomon, and E.J. Waters. 2010. The role of copper and glutathione addition and oxygen exposure in the evolution of key aroma compounds of Sauvignon blanc. In Proceedings of the 14th Australian Wine Industry Technical Conference. R. Blair et al. (eds.), p. 316. Adelaide, Australia.

Vallarino, J.G., X.A. López-Cortés, J.D. Dunlevy, P.K. Boss, F.D. González-Nilo, and Y.M. Moreno. 2011. Biosynthesis of methoxypyrazines: Elucidating the structural/functional relationship of two Vitis vinifera $O$-methyltransferases capable of catalyzing the putative final step of the biosynthesis of 3-alkyl-2-methoxypyrazine. J. Agric. Food Chem. 59:7310-7316.

Vallet, A., P. Lucas, A. Lonvaud-Funel, and G. De Revel. 2008. Pathways that produce volatile sulphur compounds from methionine in Oenococcus oeni. J. Appl. Microbiol. 104:1833-1840.

Vallet, A., X. Santarelli, A. Lonvaud-Funel, G. de Revel, and C. Cabanne. 2009. Purification of an alcohol dehydrogenase involved in the conversion of methional to methionol in Oenococcus oeni IOEB 8406. Appl. Microbiol. Biotechnol. 82:87-94.

Varming, C., M.L. Andersen, and L. Poll. 2004. Influence of thermal treatment on black currant (Ribes nigrum L.) juice aroma. J. Agric. Food Chem. 52:7628-7636.

Varming, C., M.L. Andersen, and L. Poll. 2006. Volatile monoterpenes in black currant (Ribes nigrum L.) juice: Effects of heating and enzymatic treatment by $\beta$-glucosidase. J. Agric. Food Chem. 54:2298-2302

Versini, G., S. Carlin, A. Dalla Serra, G. Nicolini, and A. Rapp. 2002. Formation of 1,1,6-trimethyl-1,2-dihydronaphthalene and other norisoprenoids in wine: Considerations on the kinetics. In Carotenoid-Derived Aroma Compounds. P. Winterhalter and R. Rouseff (eds.), pp. 285-299. ACS Symp. Series 802. Am. Chemical Society, Washington, DC.

Verstrepen, K.J., G. Derdelinckx, J.P. Dufour, J. Winderickx, I.S. Pretorius, J.M. Thevelein, and F.R. Delvaux. 2003a. The Saccharomyces cerevisiae alcohol acetyl transferase gene ATF1 is a target of the cAMP/PKA and FGM nutrient-signalling pathways. FEMS Yeast Res. 4:285-296.

Verstrepen, K.J., S.D.M. Van Laere, B.M.P. Vanderhaegen, G. Derdelinckx, J.P. Dufour, I.S. Pretorius, J. Winderickx, J.M. Thevelein, and F.R. Delvaux. 2003b. Expression levels of the yeast alcohol acetyltransferase genes $A T F 1, L g-A T F 1$, and $A T F 2$ control the formation of a broad range of volatile esters. Appl. Environ. Microbiol. 69:5228-5237.

Viegas, C.A., and I. Sá-Correia. 1995. Toxicity of octanoic acid in Saccharomyces cerevisiae at temperatures between 8.5 and $30^{\circ} \mathrm{C}$. Enzyme. Microb. Technol. 17:826-831.

Viegas, C.A., and I. Sá-Correia. 1997. Effects of low temperatures $\left(9-33^{\circ} \mathrm{C}\right)$ and $\mathrm{pH}(3.3-5.7)$ in the loss of Saccharomyces cerevisiae viability by combining lethal concentrations of ethanol with octanoic and decanoic acids. Int. J. Food Microbiol. 34:267-277.

Villamor, R.R., and C.F. Ross. 2013. Wine matrix compounds affect perception of wine aromas. Ann. Rev. Food Sci. Technol. 4:1-20.

Vogt, T. 2010. Phenylpropanoid biosynthesis. Molecular Plant 3:2-20.

Walter, M.H., D.S. Floss, and D. Strack. 2010. Apocarotenoids: Hormones, mycorrhizal metabolites and aroma volatiles. Planta 232:1-17.

Wang, J., and V. De Luca. 2005. The biosynthesis and regulation of biosynthesis of Concord grape fruit esters, including 'foxy' methylanthranilate. Plant J. 44:606-619.

Wedral, D., R. Shewfelt, and J. Frank. 2010. The challenge of Brettanomyces in wine. LWT Food Sci. Technol. 43:1474-1479.

Williams, P.J. 1993. Hydrolytic flavor release in fruit and wines through hydrolysis of nonvolatile precursors. In Flavor Science: Sensible Principles and Techniques. T. Acree and R. Teranishi (eds.), pp. 287-308. Am. Chemical Society, Washington, DC.

Williams, P.J., C.R. Strauss, and B. Wilson. 1981. Classification of the monoterpenoid composition of Muscat grapes. Am. J. Enol. Vitic. 32:230-235. 
Wilson, B., C.R. Strauss, and P.J. Williams. 1984. Changes in free and glycosidically bound monoterpenes in developing muscat grapes. J. Agric. Food Chem. 32:919-924.

Wilson, B., C.R. Strauss, and P.J. Williams. 1986. The distribution of free and glycosidically-bound monoterpenes among skin, juice, and pulp fractions of some white grape varieties. Am. J. Enol. Vitic. 37:107-111.

Winter, G., P.A. Henschke, V.J. Higgins, M. Ugliano, and C.D. Curtin. 2011. Effects of rehydration nutrients on $\mathrm{H}_{2} \mathrm{~S}$ metabolism and formation of volatile sulfur compounds by the wine yeast VL3. AMB Express 1:36.

Winter, G., T. Van Der Westhuizen, V.J. Higgins, C. Curtin, and M. Ugliano. 2010. Contribution of cysteine and glutathione conjugates to the formation of the volatile thiols 3-mercaptohexan-1-ol (3MH) and 3-mercaptohexyl acetate (3MHA) during fermentation by Saccharomyces cerevisiae. Aust. J. Grape Wine Res. 17:285-290.

Winterhalter, P. 1991. 1,1,6-Trimethyl-1,2-dihydronaphthalene (TDN) formation in wine. 1. Studies on the hydrolysis of 2,6,10,10-tetramethyl-1-oxaspiro[4.5]dec6-ene-2,8-diol rationalizing the origin of TDN and related $\mathrm{C}_{13}$ norisoprenoids in Riesling wine. J. Agric. Food Chem. 39:1825-1829.

Winterhalter, P., and S.E. Ebeler (eds.). 2013. Carotenoid Cleavage Products. ACS Symp. Series 1134. Am. Chemical Society, Washington, DC.

Winterhalter, P., and R. Rouseff. 2002. Carotenoid-derived aroma compounds: An introduction. In Carotenoid-Derived Aroma Compounds. P. Winterhalter and R. Rouseff (eds.), pp. 1-17. ACS Symp. Series 802. Am. Chemical Society, Washington, DC.

Winterhalter, P., and G.K. Skouroumounis. 1997. Glycoconjugated aroma compounds: Occurrence, role and biotechnological transformation. In Advances in Biochemical Engineering/Biotechnology. T. Scheper (ed.), pp. 73-105. Springer-Verlag, Berlin.
Winterhalter, P., M.A. Sefton, and P.J. Williams. 1990a. Two-dimensional GC-DCCC analysis of the glycoconjugates of monoterpenes, norisoprenoids, and shikimate-derived metabolites from Riesling wine. J. Agric. Food Chem. 38:1041-1048.

Winterhalter, P., M.A. Sefton, and P.J. Williams. 1990b. Volatile $\mathrm{C}_{13}$-norisoprenoid compounds in Riesling wine are generated from multiple precursors. Am. J. Enol. Vitic. 41:277-283.

Wood, C., et al. 2008. From wine to pepper: Rotundone, an obscure sesquiterpene, is a potent spicy aroma compound. J. Agric. Food Chem. 56:3738-3744.

Yanai, T., and M. Sato. 1999. Isolation and properties of $\beta$-glucosidase produced by Debaryomyces hansenii and its application in winemaking. Am. J. Enol. Vitic. 50:231-235.

Young, A.J. 1991. The photoprotective role of carotenoids in higher plants. Physiol. Plant. 83:702-708.

Young, P.R., J.G. Lashbrooke, E. Alexandersson, D. Jacobson, C. Moser, R. Velasco, and M.A. Vivier. 2012. The genes and enzymes of the carotenoid metabolic pathway in Vitis vinifera L. BMC Genomics 13:243.

Zahavi, T., L. Cohen, B. Weiss, L. Schena, A. Daus, T. Kaplunov, J. Zutkhi, R. Ben-Arie, and S. Droby. 2000. Biological control of Botrytis, Aspergillus and Rhizopus rots on table and wine grapes in Israel. Postharvest Biol. Tec. 20:115-124.

Zoecklein, B.W., J.E. Marcy, and Y. Jasinski. 1997. Effect of fermentation, storage sur lie or post-fermentation thermal processing on White Riesling (Vitis vinifera L.) glycoconjugates. Am. J. Enol. Vitic. 48:397-402.

Zozulya, S., F. Echeverri, and T. Nguyen. 2001. The human olfactory receptor repertoire. Genome Biol. 2(6):research0018. 